\title{
Responsabilizar a los migrantes del desarrollo: lecciones del laboratorio social zacatecano
}

\section{Assigning development responsibility to migrants: Lessons of the Zacatecas social laboratory}

\author{
Humberto Márquez-Covarrubias*
}

\begin{abstract}
In this article we address the alleged positive link between migration and development. We consider the state of Zacatecas in Mexico as a social laboratory and propose a conceptual triad in order to explain the main processes that take place: transnational labour, dependence on remittances and depopulation. We conceptualise the different migration and development modes that are present in Zacatecas, namely: family subsistence by remittances, transnational participative development, local economic development based on remittances and political development with migrant participation. We conclude that these modes do not really encourage local or regional development; however, they are associated to the deepening of social unsustainability and worsening of productivity in the locality of origin.
\end{abstract}

Keywords: transnational labour, depopulation, dependence on remittances, transnational participative development, local economic development based on remittances.

\section{Resumen}

En este artículo se cuestiona el presunto vínculo positivo entre migración y desarrollo. Para ello se considera al estado mexicano de Zacatecas como laboratorio social. Se postula una triada conceptual para explicar los principales procesos en curso: transnacionalismo laboral, dependencia de las remesas y despoblamiento. Posteriormente se conceptualizan las modalidades de migración y de desarrollo que se presentan en Zacatecas: subsistencia familiar por remesas, desarrollo participativo transnacional, desarrollo económico local basado en remesas y desarrollo político con participación de migrantes. Se concluye que estas modalidades realmente no promueven el desarrollo local o regional y, en cambio, se asocian a la profundización de la insustentabilidad social y deterioro productivo en los lugares de origen.

Palabras clave: transnacionalismo laboral, despoblamiento, dependencia de las remesas, desarrollo participativo transnacional, desarrollo económico local basado en remesas.

\footnotetext{
* Universidad Autónoma de Zacatecas. Correo-e: hmarquez@estudiosdeldesarrollo.net.
} 


\section{Introducción}

Abordar de manera analítica la problemática del desarrollo relacionada con los procesos migratorios puede dividirse en dos grandes campos: uno convencional, imbuido en el ideario neoliberal, difundido por gobiernos y organismos internacionales comprometidos con la necesidad de garantizar el proceso de valoración de capital en distintos planos y niveles; y otro alternativo, inmerso en el pensamiento crítico, abocado a promover opciones de desarrollo centradas en el mejoramiento sustancial de las condiciones de vida y trabajo de la mayoría de la población. Desde la visión convencional, el desarrollo de los lugares de origen se concibe como un producto de la migración. En ese sentido, las remesas se presentan como instrumento o palanca del desarrollo y los migrantes o la diáspora como agentes del desarrollo, incluso como nuevos héroes del desarrollo. Se trata de una noción de desarrollo que se reduce a una especie de estrategia paliativa de combate a la pobreza, que por supuesto no pretende generar cambios de corte estructural, político e institucional para alcanzar estadios de bienestar humano generalizado. Es una visión ideologizada que en el fondo pretende responsabilizar a los migrantes para detonar el desarrollo de sus lugares de origen —ámbitos marginales para el gran capital — sin tomar en cuenta las causas que precipitaron el subdesarrollo y la migración. Lo anterior a imagen y semejanza de la política social neoliberal, que parte del supuesto de que los pobres disponen de recursos propios (un llamado capital social, además de las remesas para el caso de los migrantes) adecuados para superar sus condiciones de pobreza. Además de atenuar la pobreza, concurre el propósito político de garantizar la gobernabilidad local, pero sin construir bases sólidas para el desarrollo local, regional y nacional. Esta concepción encubre una espiral de degradación social que explica la existencia de una migración forzada por el desempleo, la inseguridad, la violencia y la insustentabilidad. En ese contexto, se encadenan procesos de expulsión de fuerza de trabajo, despoblamiento y dependencia de remesas. Superpuesta a esta noción minimalista, el neoliberalismo en realidad promueve la idea de desarrollo como una dinámica de crecimiento económico basada en el libre comercio, la privatización y la maximización de ganancias, con el propósito último de beneficiar a las grandes corporaciones transnacionales que comandan la llamada globalización neoliberal. En esta lógica, el grueso de la población migrante simplemente deviene en insumo productivo, mercancía humana o personal desechable.

En contraste, la visión crítica del desarrollo pretende construir una explicación sobre las causas profundas de la migración para desvelar el papel asignado a los migrantes en la dinámica de acumulación de capital a escala mundial y, posteriormente, explorar la posibilidad de promover 
una transformación social sustantiva, donde participe la sociedad migrante junto con otros actores y movimientos sociales. En esa inteligencia, un concepto central es el de desarrollo desigual, entendido como un complejo proceso de diferenciación entre países desarrollados y subdesarrollados, amén de la expansión de las desigualdades sociales, que soporta la incesante concentración de capital, poder y riqueza en pocas manos frente a procesos de desmantelamiento productivo y generación de sobrepoblación que no encuentra empleo formal de calidad y que, en respuesta a la demanda de trabajo barata en países centrales, se ve forzada a emigrar para buscar el sustento propio y el de sus dependientes económicos. Desde esta perspectiva, la profundización del subdesarrollo produce migración forzada, que significa una transferencia de recursos en varios sentidos: trasvase poblacional, exportación laboral y subsidio por costos de formación. Ante el desmantelamiento de su sistema productivo y la pérdida de soberanía laboral, los países subdesarrollados se abocan a exportar gente como un mecanismo de válvula de escape ante el crecimiento del desempleo estructural y su conflictividad asociada, y como una fuente de divisas, que se ha considerado a su vez fuente del desarrollo ante la ausencia de un proyecto de desarrollo nacional alternativo, toda vez que se da continuidad al neoliberalismo sin importar sus costos sociales y económicos. Más aún, la verdadera contribución de los migrantes al desarrollo, entendido como un proceso de acumulación de capital centralizado, se da en los países desarrollados importadores de amplios contingentes de trabajadores baratos, flexibles y desorganizados. En tanto, en los países de origen, la mayor cuantía de recursos que remiten los migrantes se canaliza principalmente a la subsistencia de sus dependientes económicos.

En el contexto de la globalización neoliberal, México resalta como el principal exportador mundial de emigrantes, fundamentalmente hacia Estados Unidos, nada menos que la potencia capitalista más hegemónica y primer receptor de inmigrantes en el orbe. En el ámbito nacional, Zacatecas figura en el pináculo de la galopante migración mexicana, no sólo por estar inserta en la llamada región histórica de la migración, sino porque en términos relativos aflora como la entidad que registra el mayor dinamismo: intensidad migratoria, peso de las remesas en la economía local y despoblamiento. Pero el sello más distintivo deviene de dos aspectos de orden cualitativo. El primero concierne a la configuración de un nuevo sujeto social, plasmado en la más copiosa estructura organizacional de oriundos (Moctezuma, 2005a, 1999; Delgado y Rodríguez, 2001); y el segundo se refiere a la participación pionera en el exiguo esquema de políticas públicas que pretende vincular la migración y el desarrollo en localidades migratorias, como ocurre con los programas Tres por Uno e 
Invierte en México, aunado a la participación política de migrantes en comicios locales (García, 2003; Moctezuma, 2005b; Delgado et al., 2004).

La importancia cuantitativa y cualitativa de la migración zacatecana contribuye a crear la imagen de que la entidad es un caso ejemplar del presunto vínculo positivo entre migración y desarrollo. Desde esa tesitura, la entidad se ha considerado un caso prototípico para difundir políticas públicas acordes con un par de principios contiguos, postulados por los organismos internacionales: remesas como instrumento de desarrollo y gobernabilidad de la migración internacional. Desde otra perspectiva, el éxodo zacatecano se aviene como un caso relevante para analizar las contradicciones socioeconómicas que entrańa el proceso migratorio en una región específica y su marańa de localidades, esto nos permite apreciar a la entidad como una suerte de laboratorio social de migración y desarrollo, en la medida en que se experimentan varios proyectos e iniciativas, algunos de los cuales muestran ciertos avances (Tres por Uno), otros fracasan (Fondo Estatal de Apoyo a los Zacatecanos Ausentes) y algunos más quedan truncos (Invierte en México y Derechos Políticos Extraterritoriales), pero a final de cuentas en esta demarcación se gestan algunas de las aristas más evolucionadas del fenómeno migratorio en un contexto adverso de desarticulación productiva, precariedad laboral e insustentabilidad social (Márquez, 2005).

Desde una perspectiva crítica, el objetivo de este artículo es cuestionar la presunción de que existe un nexo positivo y unidireccional entre migración y desarrollo en regiones y localidades de alta migración internacional. Para cumplir dicho propósito es menester discurrir una explicación sobre las causas estructurales que gravitan en el proceso exportador de fuerza de trabajo y las consecuentes respuestas familiares e institucionales vinculadas al despliegue del éxodo laboral. Nuestro argumento es que en Zacatecas, tomado como caso prototípico en México, la migración no se asocia a ninguna modalidad consistente de desarrollo local, regional o nacional, y que más bien la entidad se degrada como un banco de sobrepoblación relativa acorde a la demanda estadounidense de mano de obra barata, flexible y desorganizada, bajo el influjo del modelo exportador de fuerza de trabajo (Delgado y Márquez, 2006). Es decir, con su grano de arena, los migrantes son orillados a contribuir al desarrollo de la principal potencia capitalista del orbe, no al desarrollo de sus lugares de origen, como propalan los organismos internacionales, pues ahí prevalecen condiciones de exclusión económica que no garantizan fuentes de empleo formal de calidad. Desde esta línea argumental, Zacatecas no se puede elevar mecánicamente al pedestal de los casos ejemplares de migración y desarrollo, pero sí es posible considerarlo un espejo nebuloso del deterioro del proceso civilizatorio que erosiona las bases socioeconómicas de arraigo de la población para 
dar paso a fenómenos en apariencia benéficos, como la dependencia de las remesas, y evidentemente lacerantes, como el despoblamiento. Esto habla de la necesidad de promover cambios estructurales e institucionales en distintos planos y niveles para detonar auténticamente el desarrollo.

El estudio académico de la migración zacatecana ha sido aleccionador en lo que se refiere a la revisión de cuatro dimensiones: 1) económica: centrada en la migración laboral a Estados Unidos, los vínculos de la estructura productiva con los movimientos poblacionales y las posibilidades de impulsar el desarrollo local mediante la inversión productiva de las remesas y el acompańamiento de políticas públicas (Delgado y Moctezuma, 1993; García, 2003; Delgado, 2000; Delgado et al., 2004; Moctezuma, 2005b; Márquez, 2005; Mines, 1981); 2) social: referida al surgimiento de organizaciones zacatecanas de migrantes en Estados Unidos y a la configuración de un nuevo sujeto social, el migrante colectivo, que despliega una práctica transnacional en varios planos y niveles y en programas gubernamentales como el Tres por Uno (Moctezuma, 1999, 2005a; García, 2005; Delgado y Rodríguez, 2001; Delgado et al., 2004); 3) política: orientada a la participación de los migrantes en comicios electorales (Moctezuma, 2005a), y 4) cultural: referida a los mecanismos de reproducción de los ámbitos de comunidad local en Estados Unidos (Moctezuma, 1999). Nuestra pretensión en este trabajo es recuperar algunos conceptos y ciertas ideas de esos estudios para orientar nuestra disquisición; en algunos casos procedemos a retomarlos sin más, en otros los reelaboramos y en ocasiones acuñamos conceptos nuevos de acuerdo con los propósitos específicos que orientan nuestro estudio.

El enfoque teórico que adoptamos es el de la economía política del desarrollo que, para los fines analíticos que nos hemos propuesto, abarca cuatro dimensiones: 1) geoestratégica, referida al contexto general de la integración económica entre México y Estados Unidos, que hace las veces de motor de la exportación de fuerza de trabajo barata; 2) regional, concerniente a las condiciones socioeconómicas prevalecientes en la entidad, particularmente la incapacidad estructural para generar empleo formal de calidad, esto es, la creación de bases materiales de arraigo de la población local; 3) social, trata las respuestas familiares y sociales ante las condiciones económicas estructurales adversas para la ocupación y el bienestar, y 4) institucional, alude a la respuesta gubernamental frente a la agudización del fenómeno migratorio y el deterioro de las condiciones generales de vida. Estas dimensiones se hacen presentes en distintos pasajes y secciones del texto, ya sea de manera aislada o articulada.

Para orientar nuestro análisis, proponemos un aparato conceptual distribuido en dos niveles: una triada conceptual para explicar los principales procesos en curso, esto es, transnacionalismo laboral, dependencia 
de las remesas y despoblamiento; y cuatro conceptos para caracterizar las específicas modalidades de migración y desarrollo local, es decir, subsistencia familiar por remesas, desarrollo participativo transnacional, desarrollo económico local basado en remesas y desarrollo político con participación de migrantes.

El estudio se divide en seis secciones. En la primera se expone brevemente el proceso de exportación directa de fuerza de trabajo barata mexicana en el contexto de la integración económica de México a Estados Unidos. En segundo lugar se propone el concepto de transnacionalismo laboral para el análisis regional de la migración mexicana. En la tercera se diseccionan los principales rasgos de la reproducción de la fuerza de trabajo en Zacatecas derivadas de las condiciones de estrechamiento y precarización del mercado laboral local, que configura a la entidad como una reserva de población redundante proclive a incursionar de manera itinerante o permanente en la migración laboral. En cuarto lugar se describe la particular dinámica de la migración zacatecana hacia Estados Unidos, con particular énfasis en el acelerado proceso de despoblamiento, producto de la especialización socioeconómica de la entidad: la exportación laboral. En la quinta sección se analiza la profundización de la dependencia de las remesas mediante cuatro modalidades amparadas en la idea genérica de que las remesas son fuente de desarrollo: subsistencia familiar por remesas, desarrollo participativo transnacional, desarrollo económico local basado en remesas y participación política de migrantes. Finalmente se presentan las conclusiones generales.

\section{De México para Estados Unidos: fuerza de trabajo barata}

La globalización neoliberal está organizada alrededor de la conformación de bloques regionales, la transnacionalización de los mercados financieros, la reestructuración productiva y la internacionalización de la producción (Petras et al., 2004); pero también pone en marcha una estrategia permanente de abaratamiento y precarización de la fuerza de trabajo con el fin de promover la reestructuración productiva e incrementar los márgenes de ganancia. La economía del trabajo barato llevada a extremos insospechados hasta hace pocas décadas es, hoy por hoy, uno de los principios básicos mediante los cuales opera el sistema capitalista global (Chossudovsky, 2002).

Como parte de esos procesos, México integra de lleno su economía a la reestructuración productiva estadounidense. A decir de sus promotores, en el país se instrumenta una política de crecimiento orientada a la exportación con los auspicios del Tratado de Libre Comercio de América del Norte (TLCAN). No obstante, a partir de un análisis crítico de la integración económica regional se ha puesto en evidencia que, contrario al 
propósito de exportar mercancías manufacturadas con alto componente nacional, que traería consigo el encadenamiento de los sectores productivos, en realidad desde México se está exportando masivamente fuerza de trabajo barata. Este fenómeno se ha llamado modelo exportador de fuerza de trabajo (Delgado y Márquez, 2005; Delgado y Cypher, 2005). El modelo opera mediante la articulación de tres mecanismos que reflejan el perfil asimétrico de la integración: la industria maquiladora, la maquila encubierta y la migración laboral. El modelo no se origina en el funcionamiento de un supuesto esquema aperturista de libre comercio, sino que atiende a la estrategia de internacionalización de la producción, que ha configurado una nueva división internacional del trabajo en el contexto de nuevas modalidades de intercambio desigual. En ese sentido, en el bloque económico comandado por Estados Unidos, a México se le asigna desdichadamente un papel: el de proveedor especializado de excedente económico, recursos naturales y fuerza de trabajo barata.

Entre los efectos más señalados de la integración neoliberal está la destrucción del aparato productivo troquelado en el periodo de industrialización por sustitución de importaciones, el achicamiento de la forma previamente adoptada como Estado benefactor y la liberalización copiosa de fuerza de trabajo que engrosa las filas del empleo precario, la economía informal, el desempleo y la migración laboral internacional. Esto último se puede explicar por el hecho de que con la imposición de la política neoliberal, de 1982 a 2005 apenas se han generado 8.3 millones de empleos formales, pero se ha acumulado un déficit ocupacional de 17.8 millones. Durante la vigencia del TLCAN, se han creado 3.6 millones de empleos formales, pero se han sumado 13.5 millones de nuevos demandantes al mercado laboral, esto arroja un déficit de 9.8 millones de empleos. En esas circunstancias, a partir del año 2000, la maquila y la maquila encubierta declinan en términos relativos como fuentes ocupacionales, y entonces se observa una suerte de decantación del modelo hacia su tercer mecanismo: la migración laboral, cuyo principal móvil es la inserción laboral en la economía estadounidense en condiciones de elevada precarización y exclusión social (Márquez et al., 2006). ${ }^{1}$ Así, México se presenta como el principal exportador de emigrantes del mundo. De acuerdo con estimaciones de la División de Población de Naciones Unidas (2006), México registra el saldo neto migratorio internacional promedio anual más alto

\footnotetext{
${ }^{1}$ Dado que la migración mexicana es eminentemente laboral, se conceptúa como exportación de fuerza de trabajo. La fuerza de trabajo migrante es aquella población redundante para el proceso productivo de las zonas subdesarrolladas y que hace las veces de ejército de reserva laboral de la economía desarrollada. Desde los lugares de origen se produce y vende esta mano de obra barata y desorganizada a cambio de un salario menor al promedio de lo que se devenga en las sociedades receptoras de inmigrantes, pero mayor al percibido en los lugares de origen, se trata de un pseudosobresalario (Рейa, 1995).
} 
del orbe; asimismo, y según datos del Consejo Nacional de Población (2004, 2006), ese saldo aumentó nada menos que 20.5 veces en el curso de los últimos 45 años, cuando pasó de 28 mil migrantes reportados en los años sesenta, a 575 mil entre los años de 2000 y 2005. Por añadidura, el país percibe un importante caudal de remesas, y figura como el primer receptor mundial (Banco Mundial, 2006; CMmi, 2005). Sólo en 2006, el monto de las remesas ascendió a 23.05 mil millones de dólares (Banco de México, 2007). Las remesas se consolidan como la segunda fuente de divisas en México después del petróleo y antes de la maquila y el turismo.

\section{Transnacionalismo laboral, hacia una explicación de causa-efecto}

En el periodo de entresiglos, el transnacionalismo acuñado en los centros estadounidenses de investigación ha tomado carta de naturalización y es el enfoque dominante en los estudios migratorios realizados en México, su foco de atención recae en las relaciones socioculturales que los inmigrantes construyen entre sí, en el país de destino, y con sus familiares y otros sectores sociales avecindados en los lugares de origen. Estas relaciones interpersonales configuran una red de protección que recrea los ámbitos de la comunidad originaria en los nuevos destinos y estrecha lazos de solidaridad con los pueblos de origen. A partir de la identificación de redes y prácticas sociales regulares desplegadas por los migrantes, se habla de espacio social transnacional (Rouse, 1991; Faist, 2005), acción transnacional (Glick et al., 1992) o formación social transnacional (Guarnizo, 1988). Los vínculos recurrentes entre lugares de origen y destino configuran un sistema de intercambio material y simbólico que involucra gente, dinero, bienes e información, y permite el desarrollo de una infraestructura, instituciones y cultura propias. Además, se supone que las prácticas socioculturales recrean una amplia gama de identidades y posicionamientos del sujeto migrante (Guarnizo, 2006). Sin embargo, Portes (2005) advierte que en el transnacionalismo participa un número limitado de migrantes, por lo que no se pueden sobredimensionar sus alcances, pero sugiere que 1) su estudio permite advertir una alternativa de asimilación social, política y económica a la sociedad receptora, sin que necesariamente se produzca la ruptura con la sociedad de origen; 2) los efectos en el desarrollo de los lugares, regiones y países de origen no se pueden menospreciar, particularmente por las remesas y las inversiones, y 3) el espectro de relaciones transnacionales va más allá de lo económico, político y social, pues invoca prácticas religiosas, científicas, culturales, deportivas, etcétera.

Evidentemente, no se pueden regatear los nuevos aires que este enfoque insufla a los estudios de la migración internacional, sobre todo ante el habitual clima xenófobo prevaleciente en amplios sectores de la sociedad 
de destino y de la incomprensión todavía presente en muchos sectores de los países de origen. No obstante, tampoco se puede adoptar esa perspectiva de manera acrítica, como si fuese una explicación abarcadora y suficiente. Haciendo un balance crítico, deseable por demás ante cualquier visión teórico-conceptual, podemos decir que el transnacionalismo constituye primordialmente una perspectiva descriptiva de las prácticas de corte sociocultural que entablan los migrantes. Al emplazar su mirador en el país receptor y rastrear las relaciones interpersonales que sostienen los inmigrantes con sus congéneres, este enfoque abstrae dos elementos explicativos cruciales: 1) las dinámicas estructurales que precipitan la migración laboral, y 2) el proyecto estratégico del capital transnacional plasmado en lo que se ha llamado globalización neoliberal, incluso la globalización, a secas, aparece en el transnacionalismo como un fenómeno dado que no merece discutirse sino apenas asumirse como una especie de reto o desafío. En otro nivel de discusión, advertimos una posición ambigua del transnacionalismo frente a la problemática que plantea la relación entre migración y desarrollo, pues en este renglón se aduce que las transferencias de tecnología, información, conocimiento y remesas que efectúan los migrantes eventualmente pueden abonar al desarrollo de los lugares de origen, pero en contrapartida se considera que a la postre estos envíos resultan insuficientes y con un efecto limitado. ${ }^{2}$ Por añadidura, omite el análisis de la participación de la fuerza de trabajo migrante en el desarrollo del país receptor, sólo menciona el aporte de los migrantes en su calidad de consumidores y contribuyentes fiscales; en tanto que no revisa la pérdida de recursos humanos que significa el éxodo laboral en los países de origen. Es decir, más allá de la descripción de trayectorias laborales, elude el análisis del contexto de la movilidad laboral, el papel conferido en ese entorno a los trabajadores migrantes en los lugares de origen y destino, así como los efectos socioeconómicos en los países exportadores de migrantes.

El transnacionalismo resulta insuficiente si lo que se busca es comprender a profundidad la migración mexicana a Estados Unidos en la fase actual del capitalismo mundial. En esa inteligencia, una visión crítica del transnacionalismo no deviene solamente del estudio de las prácticas socioculturales, sino de los estudios que tienen como meta encontrar la explicación fundamental de la problemática del desarrollo en los países exportadores de migrantes. En aras de contribuir a ese propósito, centramos la atención en el país y lugares de salida de la migración, sin descuidar las relaciones con el país de destino. Desde nuestra perspectiva, los estudios

\footnotetext{
${ }^{2}$ A decir de Guarnizo (2006), la migración se puede convertir en una fuerza que contribuye al desarrollo mediante la transferencia de capital y tecnología o, en su defecto, puede generar sólo un lazo de dependencia.
} 
migratorios pueden profundizar su labor analítica a partir de dos elementos entrelazados: 1) las dinámicas estructurales, consideradas como las causas de fondo que explican el contexto y los procesos principales en curso, y 2) las prácticas estratégicas, referidas al proyecto de los sujetos o agentes en función de sus intereses específicos.

A partir de esos dos criterios podemos redefinir, en términos generales, el transnacionalismo como una práctica estratégica de un agente o sujeto colectivo desplegada en el ámbito extraterritorial conforme con un proyecto específico en respuesta a condiciones estructurales que determinan el margen de maniobra con objeto de obtener ventajas y beneficios, en este sentido el trazo extraterritorial no significa la desaparición del Estado-nación. Indubitablemente, el tipo más logrado corresponde al transnacionalismo del gran capital que, en la fase actual del capitalismo, echa a andar una estrategia de reestructuración capitalista, una de cuyas vertientes es el desplazamiento de partes del proceso productivo afincado en el país sede hacia los países subdesarrollados o periféricos a fin de encontrar, entre otras ventajas, economías en el uso de la fuerza de trabajo. Desde esta óptica, conviene diferenciar los tipos de transnacionalismo según el agente o sujeto colectivo portador o no de un proyecto: gran capital, organismo internacional, Estado y fuerza de trabajo (cuadro 1).

En el contexto de la globalización neoliberal, las empresas transnacionales comandan la estrategia de desarrollo capitalista. Mediante políticas neoliberales de ajuste estructural promovidas por los organismos internacionales, verdaderos caballos de Troya, se han apropiado del mercado mundial y han penetrado las economías subdesarrolladas. Entre sus múltiples estrategias destaca la flexibilización y precarización laboral, lo mismo en los propios países subdesarrollados — destacadamente mediante la ocupación de trabajo barato y desorganizado en maquiladoras y empresas de servicios - como en los países desarrollados, que son su base de operación, por ejemplo mediante la inmigración masiva de mano de obra barata. En el caso concreto de la integración económica de México a Estados Unidos, se pone de relieve, por un lado, la ocupación de trabajo en las maquiladoras instaladas en México en condiciones laborales muy adversas, y, por el otro, por medio de la exportación de fuerza de trabajo migrante que alimenta los sectores productivos tradicionales de Estados Unidos y, en menor medida, a los sectores que encabezan el proceso de reestructuración productiva en curso.

En contrapartida, el que designamos transnacionalismo laboral se refiere a la participación de la población supernumeraria en el proceso de exportación de fuerza de trabajo y al consecuente envío de remesas a los lugares de origen para contribuir a la subsistencia familiar y, en menor medida, a la realización de obras de infraestructura y proyectos 


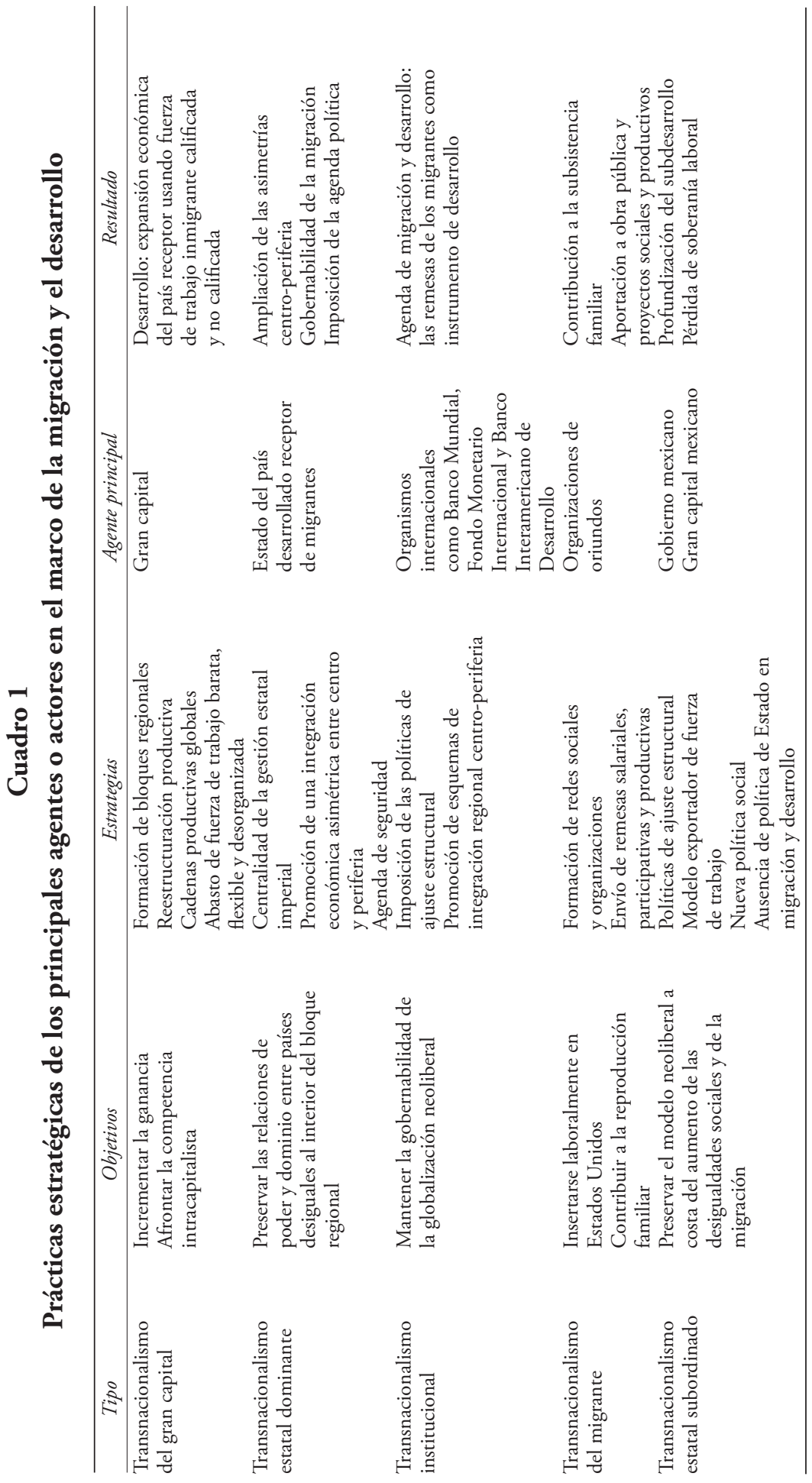


de corte social y empresarial. Así, esta modalidad de transnacionalismo tiene que considerar los momentos sucesivos de emigración, inserción laboral y envío-recepción de remesas para tener una visión abarcadora del fenómeno. Empero, a diferencia de lo que ocurre con el gran capital, esta práctica social no se ha concretado del todo debido a que 1) no dispone de un sujeto colectivo consolidado, sino de una fragmentación de actores y sujetos que actúan en los márgenes del sistema, y 2) no posee un proyecto propio puesto que su movilidad baila al son marcado por la hegemonía del gran capital, esto es, su trayectoria no responde propiamente a una estrategia adoptada de manera libre y autónoma, o a esa decisión individual de cálculo informado que pretende el neoclasicismo y sus derivados, sino que responde a un requerimiento del proceso de acumulación de capital en los países centrales y a la necesidad impuesta de satisfacer la subsistencia familiar en los lugares de origen. Más que un proyecto, por el momento existe un catálogo de reivindicaciones atomizadas y localistas. En los hechos, es importante subrayar que el transnacionalismo laboral es un subproducto del transnacionalismo del capital. Por ello, es conveniente reinterpretar las relaciones entre los migrantes y la población afín radicada en los lugares de origen como una práctica primordialmente de subsistencia con estrecho margen de autodeterminación, y no como una estrategia sociocultural inserta en el epifenómeno de la perpetuación de la migración. Por su carácter subordinado, el transnacionalismo laboral contribuye directamente al proyecto de desarrollo del gran capital y, de manera muy restringida, al desarrollo de sus lugares de origen, como se argumenta más adelante.

Además del carácter sociocultural, las relaciones transnacionales se caracterizan por dos aspectos: la formación incipiente de un nuevo sujeto social y el carácter periférico o subordinado de su práctica. Por una parte, la migración es el hecho social más constante y maduro del periodo de entresiglos circunscrito al ámbito de las prácticas sociales desplegadas por la población supernumeraria que se ve compelida a abandonar sus lugares de origen. El aspecto más visible del transnacionalismo del migrante alude a las organizaciones de oriundos. En su trayectoria, no se confronta con el transnacionalismo del gran capital, no encabeza prácticas de resistencia al proyecto de la globalización neoliberal, pues no se antepone la necesidad de promover cambios estructurales o institucionales, en realidad, así sea involuntariamente, se inscribe y alienta la lógica globalizadora. Como ocurre cuando envían remesas a sus países subdesarrollados y contribuyen a la precaria estabilidad socioeconómica, previamente devastada por el proyecto que representa la globalización neoliberal. Aunque, ciertamente, debemos introducir un matiz: los migrantes están ascendiendo en la escala de la organización social y, cada vez más, ganan una autonomía 
relativa en la gestión y defensa de sus intereses, pero esto no es válido para todo el espectro de organizaciones de migrantes. ${ }^{3}$ La elaboración de este tejido social hace posible que perduren las relaciones entre los migrantes y sus familiares y coterráneos radicados en sus lugares y regiones de origen. Estas relaciones pueden ser simbólicas o materiales, políticas o culturales, económicas o familiares. Es el caso de los envíos de remesas, la participación política binacional, el financiamiento de obras públicas y proyectos sociales, la realización de festividades y el envío de productos representativos de la oriundez, entre otros.

Por otra parte, el transnacionalismo laboral es, por antonomasia, periférico o subordinado puesto que, como señalamos, procede de un éxodo que responde a los requerimientos laborales de la economía receptora. Es periférico en cuanto no responde a una estrategia propia sino que es un afluente, importante, pero al fin afluente del flujo migratorio que va de los países subdesarrollados exportadores de emigrantes a países desarrollados importadores de inmigrantes. A diferencia del transnacionalismo hegemónico desplegado por el gran capital -que le permite, entre otras cosas, internacionalizar sus cadenas productivas-, la población migrante muestra un transnacionalismo microsocial o desde abajo. Esta práctica permite una doble lectura: obedece a dinámicas estructurales, como los requerimientos de mano de obra barata de las economías desarrolladas, y también se presenta como el conjunto de respuestas individuales, familiares y organizacionales cuya visión estratégica se constriñe a garantizar la reproducción familiar y la convivencialidad social, no el desarrollo, mediante la realización de algunos proyectos de infraestructura y productivos.

Más aún, el carácter periférico aflora cuando se toma nota de la pérdida de soberanía laboral derivada de la incapacidad estructural para generar con suficiencia fuentes de empleo formal de calidad y la profundización de las remesas para el sostenimiento de la precaria estabilidad macroeconómica y la subsistencia social de vastos sectores sociales (Márquez, 2007). Al producir población sobrante de improbable ocupación local, el mercado laboral tiene como referente principal la economía desarrollada que juega el papel central en el esquema de integración regional asimétrica. Con el influjo de las políticas de ajuste estructural, los recursos regionales y públicos son insuficientes para mantener la dinámica socioeconómica local. De manera complementaria, la población radicada en la entidad

${ }^{3}$ Como lo plantea Fox (2005), el espectro organizacional de migrantes contiene tres tipos: organizaciones orientadas a la vida social de sus lugares de origen que no interfieren mayormente en el país donde radican, éste sería el caso de las organizaciones de oriundos que examinamos en este trabajo; organizaciones abocadas a la vida social del país receptor, como puede ser el caso de sindicatos y organizaciones religiosas; y organizaciones plenamente binacionales, cuya agenda abarca la vida social de ambos países, aunque el autor sólo identifica en este rubro al oaxaqueño Frente Indígena de Organizaciones Binacionales (FIOB). 
desarrolla una gran dependencia de las remesas para solventar los gastos de subsistencia familiar, para realizar algunas obras públicas y para dinamizar, hasta cierto punto, la endeble economía local. Políticamente se ha querido presentar al éxodo laboral como una práctica de resistencia frente a la globalización neoliberal, pero más bien está inmersa en ella.

Así pues, las relaciones del transnacionalismo laboral periférico se desglosan en sendos apartados: 1) las relaciones de producción precarizadas: se trata de la inserción de fuerza de trabajo barata, flexible y desorganizada en la economía estadounidense, y 2) las relaciones sociales al interior de la sociedad migrante: se refiere a los vínculos económicos, sociales, culturales y políticos que se dan entre los migrantes radicados en Estados Unidos y sus familiares, y la población en general radicada en sus lugares y regiones de origen, para contribuir a la reproducción familiar o la realización de obras públicas y proyectos sociales, pero sin inscribirse en un proyecto alternativo de desarrollo.

Una vez que hemos intentado conceptuar el transnacionalismo laboral, en las dos secciones siguientes abordamos sus dinámicas estructurales básicas, tomando como caso lo que llamamos laboratorio social zacatecano de migración y desarrollo, para posteriormente abordar el análisis de las modalidades de desarrollo específicas inducidas a partir de la migración internacional en los lugares de origen, lo cual da cuenta del tipo de prácticas estratégicas desarrolladas en este ámbito.

\section{Rasgos socioeconómicos de la reproducción laboral en Zacatecas}

Las potencialidades del crecimiento económico en México han sido socavadas por la política neoliberal impuesta en el país y por el proceso de integración económica regional. Mientras que durante el periodo previo al neoliberalismo (1941-1982), el producto interno bruto (РІв) mostró una tasa de crecimiento promedio anual de $6.3 \%$, durante la vigencia de la política neoliberal (1983-2005) lo ha hecho en sólo 2.4\%. No es éste el lugar para emprender un análisis del aparato productivo, por el momento nos basta con señalar que en el país existe una incapacidad estructural para generar suficientes empleos formales de calidad. Además de los factores enunciados, en ese sentido influye la disminución deliberada del mercado interno, la reducción de la inversión pública y privada generadora de empleos, la proliferación de actividades ilícitas -como el narcotráfico-y la mayor presencia de la economía informal. Amén de que en detrimento de un modelo de desarrollo productivo, en México se están privilegiando las fuentes de ganancia del rentismo, la especulación y otras fuentes de ganancias extraordinarias. 


\section{Cuadro 2 \\ Población asalariada en México y Zacatecas, 2000-2006}

\begin{tabular}{ccc}
\hline Año & Nacional & Zacatecas \\
\hline 2000 & 63.1 & 52.2 \\
2001 & 62.8 & 51.7 \\
2002 & 62.3 & 54.8 \\
2003 & 62.4 & 55.1 \\
2004 & 62.5 & 53.4 \\
2005 & 58.7 & 53.8 \\
2006 & 59.9 & 53.6 \\
\hline
\end{tabular}

Fuente: Cálculos propios con datos del INEGI, Encuesta nacional de empleo y Encuesta Nacional de ocupación y empleo, varios ańos.

Nota: Los datos de 2000 a 2005 corresponden al segundo semestre; los de 2006, al primer semestre.

La economía de Zacatecas está prendida con alfileres, sus sectores productivos de por sí mermados carecen de vasos comunicantes, además de que prevalece un perfil primario con predominio de actividades de subsistencia -el empresariado es magro- y una raquítica capacidad para generar empleo asalariado, lo cual es signo de exclusión social. Como se puede apreciar en el cuadro 2, Zacatecas está por debajo de la tasa nacional de asalariados, lo cual supone que la explotación de la fuerza de trabajo, en tanto fuente básica de la ganancia, y por tanto un indicador indirecto del desarrollo económico, ha perdido importante terreno: en 2006 la entidad estaba más de seis puntos abajo de la tasa nacional. Este ambiente de insustentabilidad social se compensa en parte debido a las remesas que aportan los migrantes zacatecanos radicados en el vecino país del norte. El espejo muestra una imagen marchita: una participación en la formación del PIB instalada en los últimos lugares y un PIB per cápita, indicador convencional del desarrollo, ubicado en el cuarto lugar más bajo del país.

Si tomamos como referencia los datos de las encuestas trimestrales de empleo elaboradas por el Instituto Nacional de Estadística, Geografía e Informática (INEGI), entre 2000 y 2005 en lugar de crearse empleos en Zacatecas se registró una pérdida absoluta de -4,106 empleos. En ese lapso, la tasa de población asalariada aumentó un poco al pasar de $52.2 \%$ a $56.4 \%$ (o 53.7\%, si nos atenemos estrictamente al rubro de trabajadores asalariados, como se explica en la nota del cuadro 3), mientras que la tasa de trabajadores por cuenta propia disminuyó ligeramente al pasar de $26.6 \%$ a 25.9 por ciento.

Por lo que hace a la estructura sectorial, entre 2000 y 2005 se percibe claramente la pérdida registrada en el sector agropecuario, con -14,592 puestos de trabajo, esto se explica por la apertura comercial indiscriminada derivada del TLCAN, el inmarcesible control del mercado por las grandes agroindustrias transnacionales y el retiro estatal en el fomento produc- 


\section{Cuadro 3}

\section{Zacatecas, cambios de la población ocupada por posición en el trabajo, 2000-2005}

\begin{tabular}{|c|c|c|c|c|}
\hline & \multicolumn{2}{|c|}{ Población ocupada } & \multicolumn{2}{|c|}{ Cambios } \\
\hline & 2000 & 2005 & Absolutos & $\begin{array}{c}\text { Tasa de } \\
\text { crecimiento } \\
\text { promedio anual }\end{array}$ \\
\hline Población ocupada & 484,973 & 480,867 & $-4,106$ & -0.2 \\
\hline Trabajadores asalariados & 253,276 & 271,279 & 18,003 & 1.4 \\
\hline Patrón & 20,665 & 24,688 & 4,023 & -0.6 \\
\hline Trabajador por cuenta propia & 128,907 & 124,904 & $-4,003$ & -6.3 \\
\hline Trabajador sin pago & 82,106 & 59814 & $-22,292$ & -3.0 \\
\hline Otros trabajadores & 19 & 182 & 163 & 45.2 \\
\hline
\end{tabular}

Fuente: INEGI $(2000,2005)$. Los datos corresponden al segundo semestre de cada ańo referido. Nota: en 2005, los trabajadores asalariados se refieren a trabajadores subordinados y remunerados, que incluyen trabajadores asalariados $(258,527)$ y trabajadores con percepciones no salariales $(12,752)$.

\section{Cuadro 4 \\ Zacatecas: cambios ocupacionales por rama de actividad, 2000-2005}

\begin{tabular}{|c|c|c|c|c|}
\hline & \multicolumn{2}{|c|}{ Población ocupada } & \multicolumn{2}{|c|}{ Cambios } \\
\hline & 2000 & 2005 & Absolutos & $\begin{array}{c}\text { Tasa de } \\
\text { crecimiento } \\
\text { promedio anual }\end{array}$ \\
\hline Sector y rama & 484,973 & 480,867 & $-4,106$ & -0.2 \\
\hline $\begin{array}{l}\text { Agricultura, ganadería, } \\
\text { silvicultura, caza y pesca }\end{array}$ & 154,452 & 139,860 & $-14,592$ & -2.0 \\
\hline $\begin{array}{l}\text { Industria extractiva y de } \\
\text { electricidad }\end{array}$ & 4,622 & 5,344 & 722 & 2.9 \\
\hline Industria de la transformación & 51,587 & 39,936 & $-11,651$ & -5.1 \\
\hline Construcción & 44,646 & 45,496 & 850 & 0.4 \\
\hline Comercio & 85,312 & 97,532 & 12,220 & 2.7 \\
\hline Restaurantes y hoteles & 18,137 & 24,551 & 6,414 & 6.1 \\
\hline Comunicaciones y transportes & 9,040 & 11,726 & 2,686 & 5.2 \\
\hline Servicios profesionales & & & & \\
\hline y financieros & 7,648 & 9,374 & 1,726 & 4.1 \\
\hline Servicios sociales & 40,943 & 40,258 & -685 & -0.3 \\
\hline Servicios diversos & 45,790 & 35,957 & $-9,833$ & -4.8 \\
\hline Gobierno & 22,202 & 30,631 & 8,429 & 6.4 \\
\hline No especificado & 594 & 202 & -392 & -21.6 \\
\hline
\end{tabular}

Fuente: INEGI $(2000,2005)$.

Nota: los datos corresponden al segundo semestre de cada ańo referido. 
tivo del sector. También se destaca la pérdida de empleos en la industria manufacturera $(-11,651)$, derivada de la reducción del mercado interno, del desmantelamiento de múltiples cadenas productivas en los últimos años y del estancamiento experimentado por la industria maquiladora. En contraste, el comercio es el sector que logra sumar más empleos $(12,220)$, no obstante que la mayor parte de ellos se generan en condiciones de alta precarización e, incluso, informalidad (cuadro 4).

El panorama laboral en Zacatecas da cuenta de un acentuado proceso de precarización laboral que reduce el sector formal y orilla a amplios contingentes poblacionales a buscar alternativas ocupacionales en sectores laborales deteriorados y, principalmente, en el extranjero. A continuación se presenta un recuento general de esa dinámica descendente.

1. Raquitica importancia ocupacional de la maquila. La maquila se funda en el empleo de fuerza de trabajo barata, la baja o casi nula tasa de sindicalización, la acelerada rotación de personal y la inseguridad en el empleo. No obstante que la maquiladora ha sido el sector privilegiado en la estrategia de promoción industrial local y nacional para generar fuentes de empleo formal, la presunta ventaja comparativa basada en fuerza de trabajo barata resulta insustentable, como ocurre en el estancamiento relativo de la maquila a partir de 2000 producto de la reubicación de plantas maquiladoras en China y Centroamérica (cuadro 5).

2. Incremento de trabajadores por cuenta propia. Los trabajadores por cuenta propia son sus propios patrones. Esta forma ocupacional es precaria, pues en lugar de recurrir al trabajo asalariado, el autoempleado intensifica su propio esfuerzo laboral e incorpora trabajadores provenientes de su propia familia. Es común que carecezca de prestaciones y tiene altos niveles de intensidad y extensión de jornadas laborales. Para el primer trimestre de 2006, en Zacatecas los autoempleados representaron $26.3 \%$ de la población ocupada, un porcentaje mayor al $23.1 \%$ registrado nacionalmente (INEGI,

\section{Cuadro 5}

\section{Zacatecas: pérdida de importancia relativa de la industria maquiladora}

\begin{tabular}{lccccc}
\hline Año & Establecimientos & $\begin{array}{c}\text { Personal } \\
\text { ocupado }\end{array}$ & $\begin{array}{c}\text { Valor } \\
\text { agregado }\end{array}$ & Remuneraciones & $\begin{array}{c}\text { Insumos } \\
\text { importados }\end{array}$ \\
\hline 2001 & 86 & 5,513 & 424,455 & 237,651 & 98.7 \\
2006 & 9 & 5,683 & 141,749 & 84,441 & 97.3 \\
\hline
\end{tabular}

Fuente: INEGI, 2006, Industria maquiladora de exportación, INEGI, Aguascalientes. 
2006a). Los ocupados en micronegocios sin local constituyen el filón más crítico del rubro de autoempleados, en este caso representan $19.1 \%$ de la población ocupada en Zacatecas, que es menor al registro nacional de $21.8 \%$ (INEGI, 2006a).

3. Deterioro del poder de compra de los trabajadores. Entre 1983 y 2005, en el ámbito nacional la participación de los salarios en el PIB disminuyó en 30.8\%. En Zacatecas, en el primer trimestre de 2006, la población ocupada que no percibe ingresos representaba 14.6\%; un salario mínimo o menos, $16.5 \%$; de uno a dos salarios mínimos, $21.2 \%$; de dos a tres salarios mínimos, $17 \%$; de tres a cinco salarios mínimos, $11.4 \%$, y más de cinco salarios mínimos, 7.5\% (INEGI, 2006a). Lo cual significa que 31.1\% de trabajadores viven en condiciones sumamente deterioradas, o que apenas alcanzan un monto igual o menor al salario mínimo, o que de plano no perciben ingresos a pesar de que trabajan, muchos de estos casos se refieren a trabajo familiar de subsistencia. El 52.3\% percibe un ingreso insuficiente — dos salarios mínimos o menos- para garantizar niveles mínimos de bienestar familiar. En tanto que sólo $11.8 \%$ percibe más de cinco salarios mínimos, que representa el monto que se considera necesario para cubrir la canasta básica con suficiencia (cuadro 6).

Las condiciones generales de precarización laboral en México y Zacatecas dan cuenta de cómo se han reducido las fuentes de empleo formal bien remunerado y del modo en que se ha recurrido al abaratamiento indiscriminado de la fuerza de trabajo para incursionar en los requerimientos competitivos de la economía estadounidense, como se aprecia en el cuadro 7.

\section{Cuadro 6}

Percepción salarial en Zacatecas, 2000-2006

\begin{tabular}{lrrrrrrr}
\hline \multicolumn{1}{c}{ Nivel salarial } & \multicolumn{7}{c}{ Año } \\
& 2000 & 2001 & 2002 & 2003 & 2004 & 2005 & 2006 \\
\hline No recibe ingresos & 20.0 & 14.7 & 14.6 & 13.8 & 14.7 & 14.5 & 14.6 \\
Hasta un salario mínimo & 16.0 & 21.7 & 14.8 & 17.8 & 14.8 & 14.0 & 16.5 \\
De uno a dos salarios & 26.1 & 24.4 & 22.0 & 21.9 & 18.2 & 24.3 & 21.2 \\
De dos a tres salarios & 13.6 & 12.5 & 18.2 & 16.9 & 18.9 & 13.4 & 17.0 \\
De tres a cinco salarios & 9.2 & 9.8 & 8.9 & 9.5 & 9.7 & 10.9 & 11.4 \\
Más de cinco salarios & 6.8 & 6.2 & 7.1 & 6.0 & 4.9 & 6.4 & 7.5 \\
No especificado & 8.3 & 10.6 & 14.3 & 14.0 & 18.8 & 16.5 & 11.8 \\
\hline
\end{tabular}

Fuente: Cálculos propios con datos del INEGI, Encuesta nacional de empleo y Encuesta nacional de ocupación y empleo, varios años.

Nota: Los datos de 2000 a 2005 corresponden al segundo semestre; los de 2006, al primer semestre. 


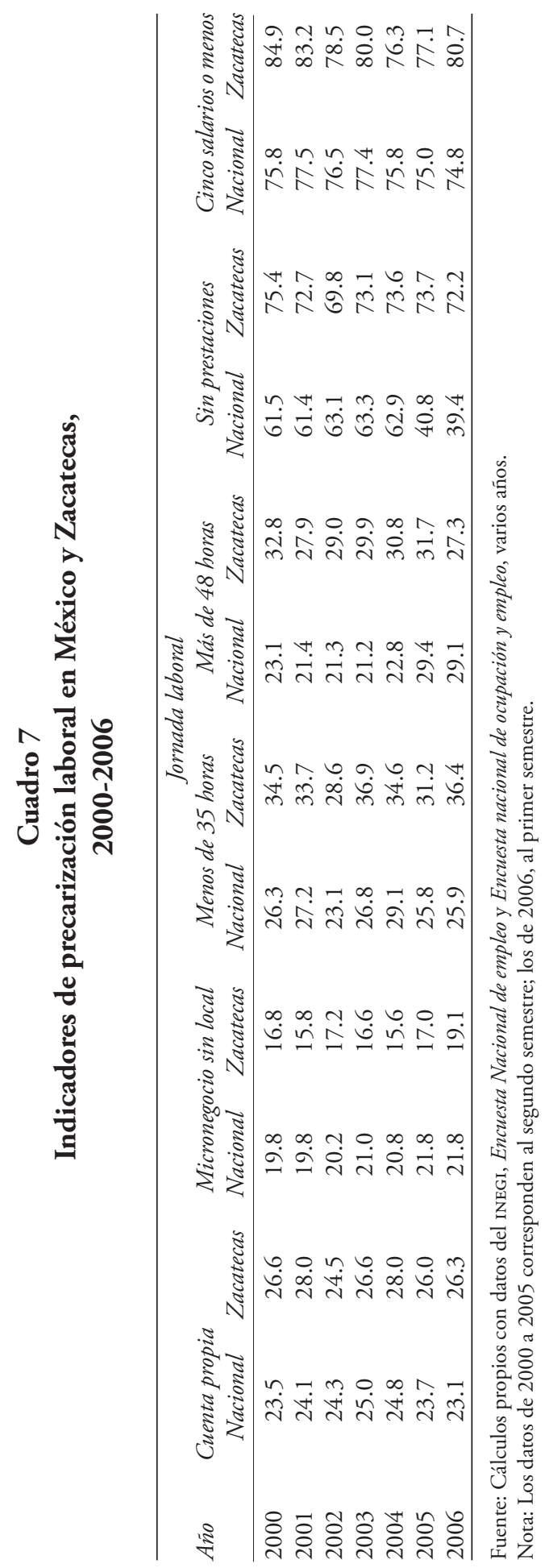




\section{Dinámica de la migración zacatecana, consolidación del despoblamiento}

Tal como sucede en todo el sistema migratorio mexicano, el zacatecano es un éxodo con raigambre histórica que se remonta a finales del siglo XIX, cuando acontece un considerable proceso de despoblamiento que alcanza mayor envergadura durante la Revolución mexicana (1910-1917). Posteriormente, el reparto agrario asume distintas modalidades migratorias: definitiva, circular y establecida, derivadas de los movimientos poblacionales internos e internacionales (Delgado et al., 2004). Actualmente, la migración internacional es uno de los fenómenos socioeconómicos de mayor preponderancia en los ámbitos nacional y regional, producto del modo específico en que se integra la economía mexicana a la estadounidense en el contexto del TLCAN, lo cual deviene no en un modelo de crecimiento exportador o secundario-exportador, como se había previsto, sino en un inexorable proceso de exportación de fuerza de trabajo mexicana barata que congestiona el flujo migratorio hacia el vecino país del norte (Delgado y Márquez, 2005).

El perfil binacional de la población zacatecana, derivado de la incesante migración internacional, aparece como el rasgo fundamental del estado. De acuerdo con estimaciones del Conapo (2005), en el ańo 2005 en Estados Unidos residían 508,924 personas nacidas en Zacatecas. Si consideramos que la población de origen mexicano residente en aquel país es de 28.1 millones, 10.6 de los cuales nacieron en México, podemos estimar que alrededor de 2.1 millones de residentes en Estados Unidos son de ascendencia zacatecana, y si tomamos en cuenta que Zacatecas contabiliza una población actual de 1.4 millones, entonces podemos plantear que hay más zacatecanos viviendo en Estados Unidos que en Zacatecas. De aquí que se trate de una entidad con fuerte raigambre transnacional, en virtud de los estrechos vínculos económicos, sociales, políticos y culturales.

Zacatecas es hoy por hoy el estado que presenta el mayor dinamismo y especialización en el incesante proceso exportador de fuerza de trabajo barata mexicana hacia Estados Unidos, así lo atestiguan los indicadores de despoblamiento, intensidad migratoria, participación de hogares, monto de remesas, peso de remesas en la economía local, entre otros, y a su vez se erige como una suerte de laboratorio social donde se ensayan incipientes procesos de desarrollo local asociados a la migración, como veremos en la sección subsiguiente. El flujo migratorio zacatecano, un afluente de la región centro-occidente del país, destaca en los indicadores sobre intensidad migratoria del Conapo (2002) al ubicarlo con el índice más alto: 2.58352 . En este indicador se sintetiza la clara primacía zacatecana en cuanto a los porcentajes de hogares que reciben remesas (13.03); 
que cuentan con emigrantes en Estados Unidos (12.18); que registran migrantes circulares (3.31), y que tienen migrantes de retorno (2.55). Lo mismo ocurre en la participación de los hogares, pues Zacatecas posee la proporción más alta de hogares con al menos un migrante en Estados Unidos: durante el primer quinquenio de la década pasada fueron $21.6 \%$ y en el segundo, 23.3\%; en ese orden de cosas le siguen Michoacán, con $19.8 \%$ y $13.4 \%$, y Guanajuato, con $18.1 \%$ y $12.3 \%$, en el primero y segundo quinquenios, respectivamente. Relacionado con lo anterior se registra un cambio en el patrón migratorio - de circular a establecidoque, entre otras cosas, implica: 1) una presencia cada vez mayor de los migrantes que fijan su residencia en Estados Unidos, pues mientras que entre 1990 y 1995 los migrantes permanentes representaban $57.5 \%$, entre 1995 y 2000 representaron $81 \%$; 2) una mayor participación femenina, entre 1990 y 1995 participaban con 20.7\% del flujo migratorio, y entre 1995 y 2000 lo hacían con $28.9 \%$; 3) descenso de la edad promedio, que pasa de 27 años a 25.9 en el mismo periodo, y 4) una prolongación de los tiempos de estancia de los migrantes de retorno, al pasar de 11 a 13 meses (Meza y Márquez, 2005; Delgado y Rodríguez, 2005).

Desde la década de los cincuenta y hasta 1990, la dinámica demográfica de Zacatecas observaba un mismo ritmo de crecimiento que representaba casi la mitad de la tendencia nacional, pero se precipita en los noventa y en 2005 conoce su nivel más bajo, para llegar prácticamente a estancarse en 2005 (gráfica I). Esta dinámica demográfica da cuenta del despoblamiento que azota las localidades migratorias.

\section{Gráfica I}

\section{Crecimiento de la población nacional y de Zacatecas, 1950-2005}

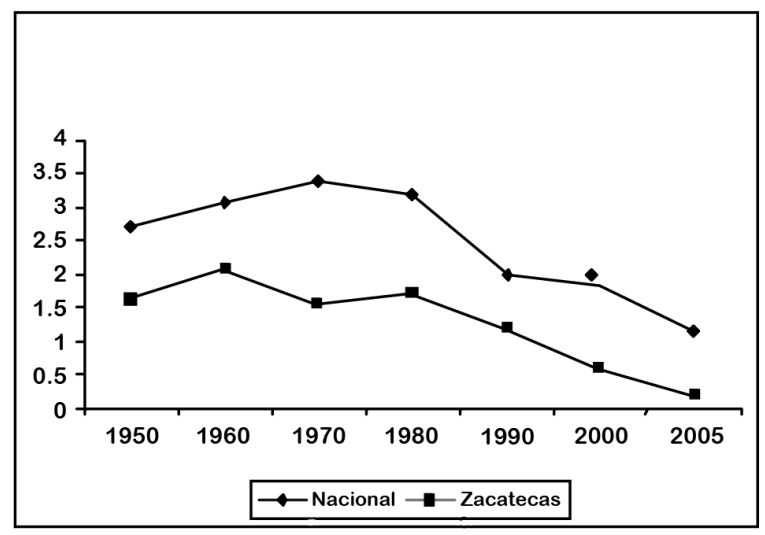

Fuente: INEGI, Censos de Población y Vivienda, 1950 a 2000 y Conteo de Población y Vivienda, 1995 y 2005. 
Entendemos por despoblamiento el proceso de abandono paulatino o acelerado del lugar de origen debido a que las bases materiales y subjetivas de arraigo -es decir, empleo, subsistencia y expectativa de vida- se han deteriorado drásticamente al grado de que la insustentabilidad social aflora y se agudiza la migración interna e internacional. En el ámbito nacional, el problema del despoblamiento se agudizó desde los noventa y se recrudeció en el quinquenio entre 2000 y 2005: 834 municipios, la tercera parte en el país, registraron ese fenómeno. En Zacatecas el problema se advierte con mayor fuerza. En el periodo comprendido entre 1990 y 2005, 37 municipios zacatecanos, de un total de $56,{ }^{4}$ experimentaron un proceso de despoblamiento pues registraron una tasa de crecimiento demográfico anual igual o menor a cero; pero en el quinquenio 2000-2005 la cantidad se elevó a $42.75 \%$ del total, 35 ya habían presentado ese problema en 2000 y 29 en 1995. Por tanto, el fantasma del despoblamiento se cierne, cada vez más, sobre el territorio zacatecano (cuadro 8). Podemos identificar tres grandes grupos de municipios frente al problema de despoblamiento:

1. Despoblamiento absoluto. Municipios cuya tasa de crecimiento es igual o menor a cero: en 2005, 42 municipios habían sido asolados, particularmente Joaquín Amaro, Atolinga, Tepetongo, Huanusco, Moyahua, Mazapil, Mezquital del Oro, Melchor Ocampo, Chalchihuites y Apozol.

2. Despoblamiento relativo. Municipios con tasas de crecimiento positivo pero menor al promedio nacional, es decir, entre 0.1 y 0.9 . En 2005 sólo cuatro municipios afrontan esta condición: Concepción del Oro, Pinos, Cuauhtémoc y Enrique Estrada.

3. Crecimiento demográfico. Municipios con crecimiento igual o superior a la media nacional, se trata de 10 municipios ubicados en la franja central del estado, que abarca la zona más urbanizada: Guadalupe, Calera, Morelos, Vetagrande, Fresnillo, Zacatecas y Pánuco, además de municipios del sureste, como Villa Hidalgo, Loreto y Villa García, región de reciente incorporación a la migración internacional.

\section{El desarrollo basado en las remesas se reduce a una nueva forma de dependencia}

Ante la reducción y precariedad del mercado laboral local, la población zacatecana busca el sustento en la economía estadounidense, sobrepasando

\footnotetext{
${ }^{4}$ Para fines comparativos no se consideran los recientemente formados municipios de Trancoso, que se desprende de Guadalupe, y Santa María de la Paz que se forma a partir del Teul de González Ortega.
} 


\section{Cuadro 8}

Zacatecas: proceso de despoblamiento

\begin{tabular}{|c|c|c|c|c|c|}
\hline & \multicolumn{5}{|c|}{ Tasa de crecimiento promedio anual } \\
\hline & 1990-1995 & $1995-2000$ & $2000-2005$ & $1990-2005$ & $1990-2005$ \\
\hline Total & 0.9 & 0.3 & 0.2 & 0.5 & 91,369 \\
\hline Joaquín Amaro & -8.3 & -1.2 & -4.4 & -4.6 & $-1,623$ \\
\hline Atolinga & -3.9 & -1.7 & -3.1 & -2.9 & $-1,496$ \\
\hline Tepetongo & -3.6 & -1.5 & -3.5 & -2.9 & $-3,825$ \\
\hline Huanusco & -2.1 & -1.6 & -4.3 & -2.7 & $-2,077$ \\
\hline Moyahua & -2.7 & -1.0 & -4.3 & -2.6 & $-2,240$ \\
\hline Mazapil & -1.1 & -3.2 & -2.7 & -2.3 & $-6,583$ \\
\hline Mezquital del Oro & -2.2 & -1.0 & -3.9 & -2.3 & $-1,044$ \\
\hline Melchor Ocampo & -4.3 & -0.9 & -1.6 & -2.3 & $-1,017$ \\
\hline Chalchihuites & -2.4 & -1.8 & -2.5 & -2.2 & $-4,146$ \\
\hline Apozol & -1.2 & -0.3 & -4.5 & -2.0 & $-2,057$ \\
\hline Susticacán & -2.3 & -1.5 & -1.7 & -1.9 & -397 \\
\hline García de la Cadena & -1.0 & -0.9 & -3.6 & -1.8 & -941 \\
\hline Momax & -1.5 & -2.0 & -1.7 & -1.7 & -802 \\
\hline Valparaíso & -2.7 & -0.8 & -1.5 & -1.6 & $-9,100$ \\
\hline Monte Escobedo & -2.8 & -0.2 & -1.8 & -1.6 & $-2,423$ \\
\hline Teul de González & & & & & \\
\hline Ortega & -1.0 & -0.3 & -3.0 & -1.5 & $-1,933$ \\
\hline Nochistlán & -1.1 & -0.9 & -2.2 & -1.4 & $-6,132$ \\
\hline Villanueva & -2.0 & 0.1 & -2.2 & -1.4 & $-6,613$ \\
\hline Gral. Francisco & & & & & \\
\hline R. Murguía & 0.0 & -2.2 & -1.9 & -1.4 & $-4,734$ \\
\hline Tepechitlán & -0.7 & -0.5 & -2.4 & -1.2 & $-1,560$ \\
\hline El Salvador & 2.5 & -4.1 & -1.6 & -1.0 & -487 \\
\hline Juchipila & -1.1 & -0.2 & -1.8 & -1.0 & $-1,932$ \\
\hline Florencia & -1.2 & 0.5 & -2.2 & -1.0 & -621 \\
\hline Concepción del Oro & -1.3 & -1.4 & 0.2 & -0.8 & $-1,548$ \\
\hline Genaro Codina & 0.1 & -0.7 & -1.6 & -0.7 & -840 \\
\hline Jerez & -0.6 & -0.5 & -0.8 & -0.6 & $-5,380$ \\
\hline Sombrerete & 0.5 & -1.1 & -1.2 & -0.6 & $-5,345$ \\
\hline Sain Alto & 0.7 & -0.9 & -1.4 & -0.6 & $-1,713$ \\
\hline Apulco & -2.0 & 1.2 & -0.7 & -0.5 & -383 \\
\hline Jalpa & -0.4 & -0.3 & -0.5 & -0.4 & $-1,497$ \\
\hline Tlaltenango & 0.6 & -0.2 & -1.6 & -0.4 & $-1,351$ \\
\hline Tabasco & -0.1 & 0.3 & -1.1 & -0.3 & -750 \\
\hline Jiménez del Teul & 0.1 & 0.5 & -1.5 & -0.3 & -230 \\
\hline Luis Moya & 0.0 & -0.1 & -0.8 & -0.3 & -520 \\
\hline Villa González Ortega & -1.0 & 0.4 & 0.0 & -0.2 & -370 \\
\hline Cañitas de F. P. & 2.5 & -1.2 & -1.5 & -0.1 & -102 \\
\hline Río Grande & 0.9 & -0.4 & -0.6 & 0.0 & -126 \\
\hline Miguel Auza & 0.3 & 0.6 & -0.9 & 0.0 & 20 \\
\hline Juan Aldama & 1.8 & -0.7 & -0.9 & 0.1 & 186 \\
\hline Villa de Cos & 1.9 & -0.2 & -1.1 & 0.2 & 858 \\
\hline Gral. Pánfilo Natera & 0.9 & 0.0 & -0.3 & 0.2 & 679 \\
\hline Noria de Ángeles & 2.0 & 0.5 & -0.9 & 0.5 & 1,034 \\
\hline
\end{tabular}


continúa...

Tasa de crecimiento promedio anual

$\begin{array}{lllll}1990-1995 & 1995-2000 \quad 2000-2005 & 1990-2005 & 1990-2005\end{array}$

\begin{tabular}{lrrrrr}
\hline Pinos & 1.3 & 0.3 & 0.5 & 0.7 & 6,624 \\
Ojocaliente & 1.6 & 1.1 & -0.4 & 0.8 & 4,204 \\
Pánuco & 1.4 & 0.5 & 1.3 & 1.0 & 2,148 \\
Cuauhtémoc & 1.9 & 0.8 & 0.8 & 1.2 & 1,840 \\
Gral. Enrique Estrada & 2.3 & 0.9 & 0.6 & 1.2 & 963 \\
Zacatecas & 1.8 & 0.9 & 1.3 & 1.3 & 23,479 \\
Villa Hidalgo & 3.2 & -0.9 & 1.8 & 1.3 & 3,119 \\
Fresnillo & 2.0 & 0.7 & 1.4 & 1.4 & 36,357 \\
Loreto & 1.0 & 1.9 & 1.7 & 1.5 & 8,853 \\
Vetagrande & 1.2 & 0.7 & 2.9 & 1.6 & 1,799 \\
Morelos & 2.4 & 1.2 & 1.6 & 1.7 & 2,400 \\
Villa García & 1.2 & 1.4 & 2.7 & 1.8 & 3,865 \\
Calera & 5.2 & 3.0 & 2.5 & 3.5 & 14,900 \\
Guadalupe & 5.2 & 0.3 & 5.7 & 3.7 & 61,979 \\
\hline
\end{tabular}

Fuentes: INEGI (1990, 2000), Censo general de población y vivienda; INEGI $(1995,2005)$ Conteo de Población y Vivienda.

de antemano las improbables oportunidades laborales nacionales. Lejos de una estrategia racional de corte individual o familiar, en el sentido neoclásico inoculado en las teorizaciones más difundidas, esta emigración responde al inmarcesible proceso exportador de fuerza de trabajo barata reseñado líneas atrás. Prescindiendo del debate teórico acerca de las causas, el afluente de recursos en dinero y en especie resultante, denominado genéricamente remesas, ha sido prontamente catalogado por los organismos internacionales y el gobierno mexicano como una fuente o motor del desarrollo regional y local. La evidencia parece contundente a primera vista: en 2006 el estado de Zacatecas captó 610 millones de dólares -1.7 millones diarios-, que se traducen en 446 dólares per cápita y $9.5 \%$ en proporción con el pIB estatal.

En ausencia de grandes inversiones públicas y privadas, ahora se parte del supuesto de que las remesas bien canalizadas en términos de inversión social y productiva se avienen como detonadores del desarrollo. En Zacatecas se dan cuatro modalidades de desarrollo local asociadas al fenómeno migratorio, pero desarticuladas entre sí. A pesar de que constituyen modalidades truncas de desarrollo, han sido exaltadas como botones de muestra para el diseño de políticas públicas de migración y desarrollo, en otras entidades en el ámbito nacional e, incluso, en otros países: 1) subsistencia familiar por remesas mediante el consumo, lo cual ha llevado a algunos autores a suponer que las remesas suplen funciones estatales y atenúan fenómenos lacerantes como marginación y pobreza; 2) el desarrollo participativo transnacional basado en las organizaciones de migrantes (Márquez, 2006a) vinculado a la realización de obra pública 
municipal y algunos proyectos sociales en los lugares de origen, con los auspicios del Programa Tres por Uno; 3) el desarrollo económico local basado en las remesas (Márquez, 2006b) inducido por la inversión productiva de las remesas, enmarcado en el Programa Invierte en México, y 4) la participación política de los migrantes en comicios locales, y recientemente federales, mediante las reformas a la Constitución Política del Estado de Zacatecas y al Código Federal de Instituciones y Procedimientos Electorales (Cofipe). Los tres primeros casos corresponden a distintos usos de remesas; el primero en realidad no constituye un programa deliberado sino una práctica social de subsistencia sin intervención estatal, pero como las remesas se consideran instrumento del desarrollo, aquí las revisamos, y el cuarto se refiere al ejercicio limitado de los derechos políticos de los migrantes en México y sus lugares de origen (cuadro 9). A continuación analizamos brevemente cada una de estas modalidades.

\subsection{Subsistencia familiar por remesas}

Varios autores han planteado la idea de que las remesas cubren un vacío de la política de desarrollo social estatal, al punto en que configuran una suerte de walfare (Goldring, 1999), debido al patrón de consumo de las remesas orientado mayormente a cubrir alimentación, vivienda, vestido, salud y educación de los miembros de la familia que radica en los lugares de origen. Por su parte, los organismos internacionales insisten en la idea de que las remesas contribuyen a reducir los niveles de pobreza y a superar las condiciones de marginación (BM, 2006; ONU, 2006), más todavía, se plantea la idea de que las remesas dotan de un poder económico a los pobres (BID, 2006).

Por nuestra parte consideramos conveniente conceptuar esta falsa modalidad de desarrollo bajo la denominación de subsistencia familiar por remesas para designar la práctica social mediante la cual los migrantes laborales insertados en la economía receptora, en condiciones de elevada precariedad y perceptores de un pseudosobresalario, envían una fracción de su salario para contribuir a la subsistencia de sus dependientes económicos avecindados en los lugares de origen. En virtud de que la familia es el sector que percibe las remesas para suplementar el consumo, el concepto que se ha venido empleando de manera consensuada es el de remesa familiar. Por nuestra parte, consideramos necesario reconceptuar el tipo de remesas inmiscuido en este caso, no ya desde una perspectiva puramente sociológica, cuya unidad de análisis es la entidad receptora, sino de acuerdo con la específica problemática de desarrollo en que se inscribe localmente. Para el caso proponemos el concepto de remesa salarial, entendido como los envíos de dinero y en especie efectuados por los migrantes para con- 


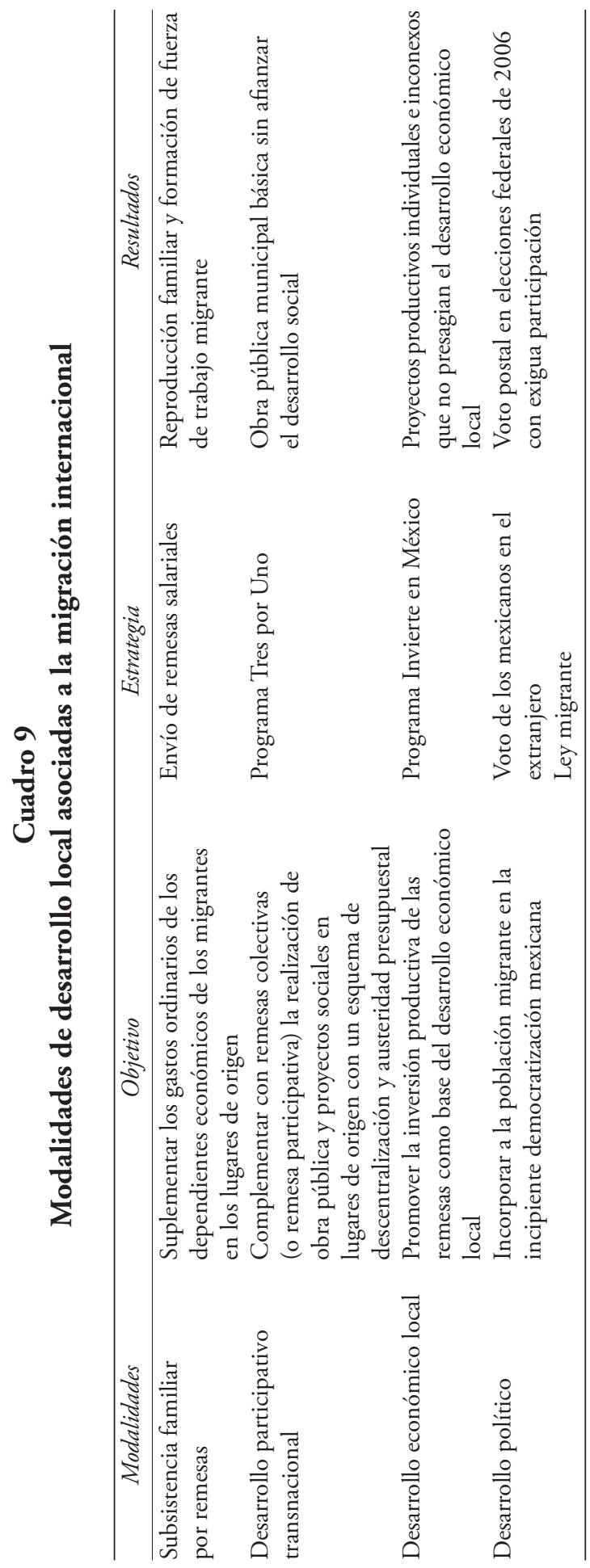


tribuir a la subsistencia de sus familiares mediante recursos canalizados al consumo en alimentación, vestido, salud y educación, es decir, se trata de rubros que conforman los bienes-salario (Márquez, 2006a). En esa medida, la mayor parte del caudal de remesas captadas en el país proviene del salario devengado por los migrantes laborales en Estados Unidos, muy por encima de los otros tipos de remesas.

La probable incidencia de la remesa salarial en el desarrollo está situada en el umbral más bajo, justamente en el que apenas se antepone la satisfacción de las necesidades básicas del círculo familiar. Esta condición se hace más notoria cuando se ratifica el hecho de que, en su mayoría, el uso de estas remesas se destina a la subsistencia, y si tomamos en cuenta el abandono estatal -con el influjo neoliberal- de los componentes principales del bienestar social, las remesas se consolidan inexorablemente como el cimiento, una especie de paliativo, del bienestar social de las localidades y regiones de origen de los migrantes. En ese panorama de regresión social, los organismos internacionales difunden la idea de que la migración internacional configura el rostro humano de la globalización y de que las remesas son fuente del desarrollo, sin mencionar los estragos de las políticas neoliberales de ajustes estructurales y la apertura comercial indiscriminada; es decir, se propone la idea de que los migrantes y su población afín amasan un cierto capital social, articulado por las remesas, que puede ser activado para superar las condiciones de marginación y pobreza existentes en sus lugares de origen y arribar, a la postre, al desarrollo comunitario. Por lo visto, existe una fuerte carga ideológica en el discurso del que llamamos transnacionalismo institucional.

Para captar mejor el problema, proponemos el concepto de dependencia de las remesas entendido como la necesidad de allegarse divisas por medio de la exportación de fuerza de trabajo a fin de mantener el precario equilibrio macroeconómico y cubrir la subsistencia familiar entre amplios sectores de la población, ante la incapacidad de promover el desarrollo nacional, regional y local debido a la subordinación de la economía nacional (periférica) a los designios de la economía central que comanda el bloque económico regional, y debido a la consecuente pérdida de soberanía laboral que imposibilita la generación de suficientes fuentes de empleo formal de calidad para la población en edad laboral. A nivel macro, las remesas se han consolidado como la segunda fuente de divisas del país. Muy a su pesar, la exportación de migrantes coadyuva al sostenimiento de la política neoliberal.

A nivel micro se aprecia el influjo de las remesas en los ámbitos local y regional, mediante el consumo familiar, la realización de obras públicas financiadas en parte por los migrantes y las pequeñas inversiones de migrantes empresarios. Sin embargo, el efecto más significativo deviene de 
las remesas salariales. En ese tenor, Zacatecas, de nueva cuenta, se sitúa en la cúspide: el porcentaje de hogares receptores de remesas asciende a $13 \%$; la proporción de las remesas en el ingreso familiar total, a 61.9\%; los hogares en que las remesas constituyen la principal fuente de ingresos, $61.5 \%$, y los hogares donde las remesas representan la única fuente de ingresos, 34.8\% (Delgado et al., 2004). En el ámbito regional la repercusión de la remesa salarial es menos clara. Al respecto se puede considerar que, en contraste con el alto grado de intensidad migratoria, Zacatecas se ubica en una franja intermedia -en el tercero de siete estratos- respecto de otras entidades en lo referente a los índices de bienestar social elaborados por el INEGI (2000b).

\subsection{Desarrollo participativo transnacional}

Con el fin de evidenciar el nexo entre migración y desarrollo en el ámbito local articulado por las remesas de los migrantes, proponemos el concepto de desarrollo participativo transnacional, entendido como la política estatal para la realización de obra pública y proyectos sociales en las localidades de alta incidencia migratoria, con un esquema de descentralización y la participación en coinversión de los tres niveles de gobierno -federal, estatal y municipal-y los migrantes organizados, según las pautas de la nueva política social que supuestamente pretende resarcir los estragos sociales del neoliberalismo en un entorno de gobernabilidad local (Márquez, 2006a). De la misma manera que en el caso anterior, es conveniente superar la conceptuación sociológica para precisar el proceso de desarrollo inducido por un tipo específico de remesas, en este caso recodificamos el concepto de remesa colectiva, ${ }^{5}$ centrada en el migrante que remite la remesa, el migrante colectivo, para designar un nuevo tipo de remesa, la remesa participativa, que alude al recurso en dinero que los migrantes organizados aportan para participar en el programa de obra municipal y proyectos sociales, en conjunción con recursos fiscales de los tres niveles de gobierno, es decir, con un esquema de desarrollo participativo. Desde esta perspectiva, la remesa participativa no se puede designar simplemente como remesa colectiva, porque -cuando menos en su vertiente institucionalizada- donde hay mediación estatal, figura como un componente más del esquema de coinversión que el Estado ha diseñado mediante el patrón de la descentralización, la nueva política social y la austeridad

${ }^{5}$ La remesa colectiva alude a los envíos, en dinero o especie, de las organizaciones de migrantes a grupos sociales, organizaciones e instancias gubernamentales con el propósito de realizar obras públicas y sociales en los lugares de origen; el caso más prototípico es la remesa canalizada al Programa Tres por Uno (Moctezuma, 1999; Goldring, 1999; García, 2001). A diferencia de las llamadas remesas familiares, donde quien remite es un migrante individual, a lo sumo los migrantes miembros de una familia, en la remesa colectiva el sujeto remisor es el migrante colectivo. 
presupuestal neoliberal. Esto sin descargo de que la remesa participativa también expresa una práctica social solidaria y cooperativa de los migrantes organizados para con la población de sus lugares de origen, aunque quizá sin proponérselo abonan al interés estatal de generar condiciones de gobernabilidad local sin proyectar institucionalmente el desarrollo.

Uno de los aspectos que le ha merecido gran visibilidad a la migración zacatecana en la palestra internacional es la participación de sus organizaciones de migrantes en el Programa Tres por Uno. Actualmente se reconoce que conforman el espectro organizacional más extendido y numeroso en Estados Unidos, pues cuenta con más de 260 clubes, que a su vez se aglutinan en 16 federaciones (Moctezuma y Pérez, 2006). Empero, conviene señalar que las organizaciones de zacatecanos, desde la óptica del desarrollo, no están completamente diversificadas, cuando menos por dos razones básicas: 1) sólo actúan en sus lugares de origen, dado que no han alcanzado un desdoblamiento binacional que les permita actuar simultáneamente en la sociedad estadounidense y en la mexicana a la vez, ya que sus acciones se dirigen sobre todo a sus lugares de origen, en México, y sólo el gobierno mexicano los concibe como interlocutores, no así el estadounidense, y 2) sus prácticas se limitan a contribuir en las obras públicas y proyectos sociales en sus lugares de origen, es decir, su aporte está acotado por los programas gubernamentales, entre otros factores por el techo presupuestal anual austero, sin que hayan creado vasos comunicantes con otros sectores sociales ni hayan afianzado todavía organizaciones paralelas, por lo cual distan de ser un sujeto del desarrollo local, aun cuando puede hablarse del surgimiento de un nuevo sujeto social inscrito en la lógica del desarrollo participativo transnacional (Márquez, 2006a).

En 2004, mediante el Programa Tres por Uno se invirtieron 538.8 millones de pesos. Si se suman las cuatro fuentes de financiamiento (migrantes, municipio, estado y federación), dicha cantidad representa 3.24\% de lo que recibe el país por las llamadas remesas familiares. No obstante, en localidades pertenecientes a entidades como Zacatecas y Jalisco su peso es significativo en relación con los montos de inversión pública en infraestructura y servicios. El espectro de obras realizadas en este programa abarca desde la pavimentación de calles y rehabilitación de iglesias, hasta obras de infraestructura productiva como carreteras y presas.

En el caso de Zacatecas -entidad con mayor participación en el programa, amén de que ahí se gestó-, de 1993 a 2005 se realizaron 1,500 proyectos con remesas colectivas con una inversión de los diferentes fondos concurrentes cercana a los 60 millones de dólares. En el ámbito nacional, con el Programa Iniciativa Ciudadana Tres por Uno se han realizado más de 3,000 proyectos de infraestructura básica. A pesar de lo bajo del presupuesto federal para este programa, que no ha rebasado en ningún año 
Cuadro 10

Zacatecas, Programa Tres por Uno, 2005

\begin{tabular}{lccc}
\hline \multicolumn{1}{c}{ Rubro } & Obra & Inversión & Porcentaje \\
\hline Carreteras & 31 & $56,956.5$ & 28.35 \\
Templos & 34 & $24,770.6$ & 12.33 \\
Pavimentación de calles & 51 & $22,682.5$ & 11.29 \\
Asistencia social y servicios & & & \\
comunitarios & 37 & $20,911.2$ & 10.41 \\
Educación & 28 & $16,325.6$ & 8.13 \\
Electrificación & 69 & $18,964.9$ & 6.95 \\
Urbanización & 45 & $12,468.0$ & 6.21 \\
Drenaje & 24 & $9,574.0$ & 4.77 \\
Lienzos charros & 10 & $6,500.8$ & 3.24 \\
Productivos & 16 & $4,497.9$ & 2.24 \\
Caminos & 5 & $3,201.4$ & 1.59 \\
Deportivos & 7 & $3,338.7$ & 1.66 \\
Agua potable & 15 & $1,976.0$ & 0.98 \\
Salud & 4 & $1,315.2$ & 0.65 \\
Becas & 9 & $1,242.0$ & 0.62 \\
Planeación del desarrollo & & $1,144.3$ & 0.57 \\
Total & & $200,870.2$ & 100 \\
\hline
\end{tabular}

Fuente: Segundo informe de gobierno.

los 15 millones de dólares (frente a los 54 millones de dólares diarios que enviaron los migrantes mexicanos de remesas familiares en 2005), es uno de los programas sociales de los tres niveles del gobierno mexicano con mayor aceptación en los lugares de origen y las organizaciones migrantes, que a su vez ha tenido resonancia internacional.

Esta modalidad persigue un desarrollo social limitado a la creación de infraestructura social básica (obra pública municipal) y la convivencialidad (proyectos sociales). Es decir, no pretende ni mucho menos mejorar las condiciones socioeconómicas de la población ni propiciar cambios en las dinámicas estructurales e institucionales que gravitan en la perpetuación del fenómeno migratorio, de tal suerte que se orienta por los objetivos políticos estatales del desarrollo participativo y no por las aspiraciones de desarrollo de la población, que entre otros elementos incluye la generación de bases materiales y subjetivas de arraigo. Amén de que tiene verificativo sólo en aquellas localidades que disponen de organizaciones de migrantes en Estados Unidos dispuestas a aportar sus propios recursos, y con la restricción de la austeridad presupuestal gubernamental autoimpuesta por la política neoliberal.

Sin embargo, en un balance general, podemos advertir que este proceso particular de desarrollo trae aparejados efectos que bien podemos determinar como positivos y negativos. Por una parte, estimula la creación de 
nuevas organizaciones de migrantes y apuntala la de obra pública municipal; por la otra, se excluye a localidades sin organizaciones de migrantes, hay obras de mala calidad, las autoridades imponen obras, se registran casos de corrupción y el fondo fiscal es austero frente a las necesidades sociales prevalecientes.

\subsection{Desarrollo económico local basado en las remesas}

Mientras que conceptualmente el desarrollo económico local se fundamenta en la inversión privada de actores locales e inversión pública complementaria, y es un componente del desarrollo local, el desarrollo económico local basado en las remesas se funda en la inversión productiva de las remesas, en este caso de los migrantes empresarios mediante la ejecución de pequeños proyectos en los lugares de origen de los migrantes (Márquez, 2006a). La promoción de esta modalidad deviene de la idea lanzada por el Banco Interamericano de Desarrollo (BID), según la cual el motor del desarrollo es la inversión productiva de las remesas (Fomin, 2004; Iglesias, 2002; BID, 2000); en ese caso el desarrollo económico local se define como el "aumento de la competitividad de las comunidades locales que conduce al incremento de ingreso y empleo en las zonas de alta intensidad migratoria de México" (вID, 2000: 5). Sin duda, ésta es una definición ambigua de desarrollo económico local pues plantea el logro de mejoras sociales (ingreso y empleo) mediante la inversión empresarial, que persigue antes que nada la ganancia. Las remesas se invocan como el recurso principal -incluso en sustitución de recursos públicos y privados-, aun cuando se señala que para canalizar las remesas a los proyectos empresariales se dispondrá de la participación del gobierno local y de inversionistas privados de la región, por lo que conviene diferenciar este tipo de remesa como remesa productiva, entendida como los recursos de inversión canalizados a microproyectos por los migrantes empresarios en sus lugares de origen.

El actor protagónico ya no sería el trabajador migrante que envía remesas para la subsistencia de la familia ni las organizaciones de migrantes que envían recursos para la realización de obras públicas y sociales, sino el migrante empresario asociado o no a inversionistas locales y regionales (García, 2003; Moctezuma, 2005a). Además de que serían los migrantes empresarios los principales aportadores de recursos para el supuesto fondo de inversión, no necesariamente serían el sector clave del desarrollo por lo que hace a la toma de decisiones: en lugar de procurar un ensanchamiento organizativo de la base social con miras a la creación de alternativas perdurables de desarrollo, se postula una decantación hacia los intereses idealizados de un sector privado muchas veces incipiente. 
Incluso este modelo podría estar ideado para que los recursos de los migrantes financien o soporten los proyectos del empresariado local y extralocal. Por si fuera poco, y no obstante que es una modalidad selectiva, requiere la participación de la mayor parte de la población migrante, dado que el modelo no puede operar sin que sigan fluyendo las remesas salariales y participativas, pues éstas cumplen el papel de coadyuvantes en la consecución de una cierta estabilidad socioeconómica de las zonas migratorias. La meta es promover la creación de empresas y, en algunos casos, comercializar productos en el llamado mercado paisano, sin que ello signifique el mejoramiento general de las condiciones de vida de la población: el móvil fundamental es la rentabilidad, la ganancia y las inversiones. Se trata, pues, de desarrollo económico local y no de desarrollo local, cuando menos conceptualmente. Ésta es la principal paradoja de la modalidad, pues mientras que la mayor parte de la población migrante participa enviando remesas familiares y colectivas - con lo cual se crea una cierta estabilidad socioeconómica y se abona a la gobernabilidad local-, sólo un sector clave, el empresariado, eventualmente podría beneficiarse de los frutos del supuesto desarrollo económico local.

\subsection{Desarrollo politico con participación de migrantes}

Entendemos por desarrollo politico con participación de migrantes la incursión de los migrantes en el ejercicio de sus derechos políticos como mexicanos en la incipiente democracia representativa en los ámbitos local, estatal y nacional. A diferencia de las tres modalidades analizadas previamente, no se basa en el uso de las remesas. En términos prácticos, esta modalidad de desarrollo aparece de manera trunca desde su diseńo, puesto que, en el caso de la participación local y estatal en Zacatecas, el ejercicio de los derechos políticos se limita a ser votado para diputado local o presidente municipal con la anuencia de los partidos políticos con registro, como quedó plasmado en la reforma a la Constitución Política del Estado de Zacatecas en agosto de 2003, el primer ejercicio en su género en México. En el plano federal se constriñe al derecho a votar en el extranjero sólo para presidente de la República. ${ }^{6}$

El debate político en Zacatecas brilla por su ausencia. Por una parte, los partidos políticos pergeñan un discurso pragmático que antepone sus

${ }^{6}$ En febrero de 2005 se aprobó la reforma al Código Federal de Instituciones y Procedimientos Electorales (Cofipe) que permite a los mexicanos que residen en el extranjero votar en las elecciones federales para presidente de la República con la modalidad del voto postal. Para las elecciones de julio de 2006 apenas se registraron 40,854 migrantes de 10 millones de votantes potenciales, entre otros factores, la baja participación electoral obedeció a deficiencias organizacionales en la instancia promotora, la falta de información, la prohibición de que los candidatos hicieran campańa proselitista en el extranjero y la adopción de la modalidad menos propicia, el voto postal. 


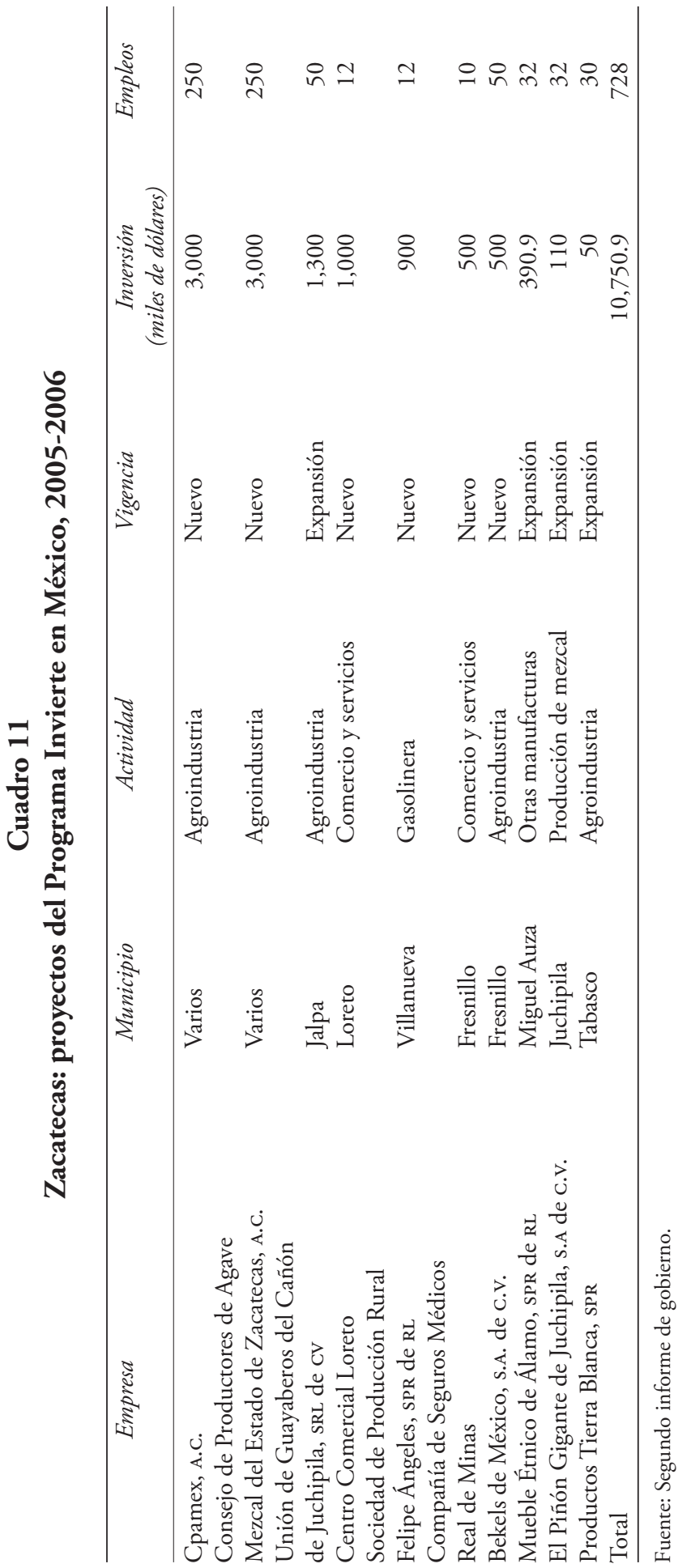


intereses inmediatos, de índole electoral, antes que discutir a profundidad posibles alternativas acerca de la problemática del desarrollo asociada a la migración. Pese a que el Congreso local ha dado cabida a dos diputados que ostentan la representación de la sociedad migrante, merced a una reforma político-electoral local, en los hechos éstos han venido a represar los intereses políticos de los partidos que los cobijan -en este caso el Partido Revolucionario Institucional (PRI) y el Partido de la Revolución Democrática (PRD)-. Lo mismo puede decirse de los pocos presidentes municipales provenientes del sector migrante, como el panista Andrés Bermúdez, mejor conocido como El Rey del Tomate, en Jerez, quien no logró cumplir las elevadas expectativas que despertara. Por otra parte, las organizaciones de migrantes, como la Federación de Clubes del Sur de California y el Frente Cívico Zacatecano, por citar un par de ejemplos, si bien incrementaron su presencia mediática y su voz ha estado presente en diversos foros académicos y políticos en su afán de encabezar iniciativas políticas, económicas y sociales -algunas de las cuales prosperaron, como la referida reforma electoral-, todavía adolecen de la falta de contrapartes locales que cierren la pinza del accionar sociopolítico, a pesar de que ya se han hecho esfuerzos por generar esas instancias de actuación local, amén de que no han logrado cristalizar un proyecto político consistente. Esto no significa, empero, que la participación política de los migrantes esté pervertida del todo o que se haya cancelado de manera definitiva la injerencia de políticos migrantes eventualmente portadores de proyectos y propuestas renovadoras, hasta cierto punto, del quehacer político, el trabajo legislativo y el diseño de políticas públicas.

En el plano institucional, la alternancia electoral que permitiera el arribo al poder al PRD en 1998, luego de una larga hegemonía priista, no se ha traducido en el diseño de una política migratoria de nuevo tipo. Si bien en los planes de desarrollo de los sucesivos gobiernos encabezados por Ricardo Monreal y Amalia García ya se reconoce la importancia crucial del fenómeno migratorio para Zacatecas, en términos prácticos no se ha diseñado e instrumentado una nueva institucionalidad (la creación del Instituto Estatal de Migración, de corte asistencial, es insuficiente) ni un esquema de políticas públicas que se aboquen, así sea con las limitaciones del caso, a generar cambios socioeconómicos que o bien ataquen las causas de la migración o bien encausen el potencial que significa la diáspora zacatecana para detonar alternativas de desarrollo local y regional, o ambas cosas. A lo sumo se ha reproducido localmente el esquema operativo de las políticas federales y el diseño programático de otros gobiernos estatales, lo cual es paradójico si tomamos en cuenta que la alternancia electoral despierta siempre el interés para cambiar las políticas públicas en los temas de mayor importancia, como ocurre con la migración zacatecana, y sobre 
todo si tomamos en cuenta que la práctica social de los migrantes y la importancia relativa del fenómeno han ido troquelando a la entidad como una suerte de laboratorio social de la migración transnacional.

$\mathrm{Al}$ ser una modalidad supeditada a la democracia representativa, que responde exclusivamente a la agenda política del actual sistema de partidos y que limita el ejercicio pleno de los derechos políticos como ciudadanos mexicanos, esta forma de desarrollo se aviene, en verdad, como un obstáculo para dar cauce a un proyecto político emanado de la sociedad migrante y para generar nuevas políticas públicas en materia de desarrollo y migración; en cambio abona notablemente al proceso de legitimación tan caro a la clase política justo en un escenario donde el descrédito se esparce sobre los sucesivos gobiernos neoliberales y entre todos los partidos que contribuyen a su sostenimiento sin el respaldo popular.

\section{Conclusión}

El principal aporte de nuestro artículo consiste en hilvanar una explicación crítica de los resortes estructurales de la migración laboral mexicana y zacatecana hacia Estados Unidos, así como las modalidades truncas de desarrollo inducidas en las localidades de alta migración mediante el uso diferenciado de las remesas y la participación de distintos tipos de migrantes. Para analizar el contexto recurrimos al concepto de modelo exportador de fuerza de trabajo barata, que explica los mecanismos que atribuyen un papel específico a la mano de obra mexicana en la reestructuración productiva estadounidense, y derivado de lo anterior armamos un aparato conceptual para explicar los procesos específicos de desarrollo instrumentados en la entidad, particularmente en las localidades de alta migración, al respecto identificamos cuatro: subsistencia con remesas, desarrollo participativo transnacional, desarrollo económico local basado en las remesas y desarrollo político con participación de migrantes. Para dar cuenta de esos procesos propusimos una nueva tipología de remesas acorde al proceso de desarrollo específico y no a criterios sociológicos (como remesa familiar y colectiva): remesa salarial (subsistencia familiar), remesa participativa (desarrollo participativo transnacional) y remesa productiva (desarrollo económico local).

Derivado del análisis del contexto y los procesos, podemos extraer las siguientes conclusiones generales, a manera de lecciones que brinda la experiencia migratoria zacatecana.

- La migración zacatecana a Estados Unidos se sitúa en el pináculo de la estampida poblacional mexicana y prohíja sus aristas más evolucionadas merced a su dinamismo, madurez e historicidad, al 
punto que puede considerarse a la entidad como un laboratorio social transnacional, útil para el análisis del problema migratorio y el diseño de alternativas de desarrollo. No así como un caso exitoso y paradigmático de la migración y el desarrollo, ya que los resultados son contrastantes: por una parte se advierte un ascenso organizacional de los migrantes que se traduce en una contribución para la realización de obra pública y proyectos de orden social y productivo, amén del aporte de los migrantes individuales para el consumo familiar, pero, por otra parte, el fenómeno migratorio está claramente asociado a la profundización de condiciones de insustentabilidad social, despoblamiento, desarticulación productiva y la consolidación de la población como una reserva laboral a disposición de la economía estadounidense.

- El creciente despoblamiento que experimenta Zacatecas, en vías de consolidarse como una pérdida neta irreversible, significa no sólo el derroche de fuerza de trabajo y abandono concomitante de actividades económicas, sino también la pérdida de riqueza potencial. Este retroceso sociodemográfico encuentra apenas una mínima compensación con el surgimiento de un nuevo sujeto social encarnado en las organizaciones de migrantes asentadas en Estados Unidos y que estrechan vínculos solidarios con sus lugares de origen. Por otra parte, el despoblamiento lo aprovecha el Estado para destinar menos recursos fiscales y disminuir la participación política de la entidad en la actividad parlamentaria, puesto que el peso poblacional se emplea como criterio distributivo.

- Las modalidades de desarrollo asociadas a la migración que hemos analizado nos ilustran cómo están acotadas estructural e institucionalmente, puesto que se mantiene en vigor el esquema de integración asimétrica que genera ciclos de desacumulación, desarticulación productiva, exclusión económica, precarización laboral y aumento de las desigualdades sociales, además de que se mantienen las políticas de ajuste estructural acicateadas con políticas asistencialistas que no resuelven de fondo problemas como pobreza, marginación y migración. A la postre, las modalidades de migración y desarrollo sólo atribuyen a los migrantes la responsabilidad de promover el desarrollo en sus lugares de origen, como justificación del repliegue de las funciones estatales en materia de gestión del desarrollo, como prescribe el llamado Consenso de Washington. En los hechos, en lugar de desarrollo local se crea una dependencia de las remesas. Por tanto, es un error plantear que el 
caso zacatecano ilustra una relación exitosa entre migración y desarrollo; al contrario, ejemplifica cómo en ausencia de un verdadero proyecto de desarrollo, la incesante exportación de fuerza de trabajo conduce a la dependencia de las remesas, el despoblamiento y la exclusión social, aunque se mantiene la dinámica que contribuye al desarrollo de los países centrales receptores de los contingentes laborales inmigrantes precarizados y desorganizados.

- La formulación migración y desarrollo, pensada para los lugares y regiones de origen, pretende expresar una relación de términos correlativos cuando en realidad son antitéticos: uno alude a la exportación de fuerza de trabajo, al despoblamiento y a la exclusión económica; el otro a la profundización del subdesarrollo que afirma una dependencia de las remesas. Por lo que no es descabellado afirmar que la idea de que la migración produce desarrollo resulta unidireccional y mecanicista, además de ahistórica y descontextualizada, en suma irresoluble y falsa.

\section{Bibliografía}

Banco de México (2007), Informe anual 2006, Banco de México, México.

Banco Mundial (2006), "Cerca de casa: el impacto de las remesas en el desarrollo de América Latina. Cifras más importantes”, http:// siteresources.worldbank.org/INTLACOFFICEOFCEINSPA/Resources/RemittancesFactSheet06_Spa.pdf, 20 de agosto de 2006.

BID (Banco Interamericano de Desarrollo) (2000), "Capitalización de remesas para desarrollo económico local", Memorando de donantes, México.

BID (Banco Interamericano de Desarrollo) (2006), Las remesas como instrumento de desarrollo, BID-Fomin, Washington.

CMMI (Comisión Mundial sobre las Migraciones Internacionales) (2005), "Las migraciones en un mundo interdependiente: nuevas orientaciones para actuar", Informe de la CMMI, octubre, Ginebra.

Chossudovsky, Michel (2002), Globalización de la pobreza y nuevo orden mundial, Siglo XXI-unam, México.

Conapo (Consejo Nacional de Población) (2002), Indice de intensidad migratoria México-Estados Unidos, 2000, Conapo, México. 
Conapo (Consejo Nacional de Población) (2004), "Pérdida neta anual por migración a Estados Unidos por periodo, 1960-2003”,www. conapo.gob.mx/mig_int/series/g06.ppt, 3 de octubre de 2004.

Conapo (Consejo Nacional de Población) (2005), Migración MéxicoEstados Unidos. Panorama regional y estatal, Conapo, México.

Conapo (Consejo Nacional de Población) (2006), "El Conapo, el INEGI y el Colmex concilian cifras sobre la dinámica demográfica del país para el periodo 2000-2005", comunicado de prensa 37/06, www.CONAPO.gob.mx/prensa/2006/372006bol.pdf, 19 de septiembre de 2006.

Delgado Wise, Raúl (2000), “Consideraciones sobre la estructura económica y social de Zacatecas de cara al siglo xxı”, en Rodolfo García Zamora y Juan Manuel Padilla (coords.), Los retos demográficos de Zacatecas en el siglo XXI, Universidad Autónoma de Zacatecas, México.

Delgado Wise, Raúl y Héctor Rodríguez (2001), "The emergente of collective migrants and their role in Mexico's local and regional development", Canadian Journal of Development Studies, XXII (3), Otawa, pp. 747-764.

Delgado Wise, Raúl y Humberto Márquez (2006), “The Mexico-Unites Status Migratory System: Dilemmas of Regional Integration, Development, and Emigration", ponencia presentada en la Conferencia Migration and Development: Perspectives from the South, 10-13 de julio, Bellagio, Italia.

Delgado Wise, Raúl y Humberto Márquez, "Migración, políticas públicas y desarrollo. Reflexiones en torno al caso de México", ponencia presentada en el Seminario Problemas y Desafíos de la Migración y el Desarrollo en América, Cuernavaca, Red Internacional de Migración y Desarrollo, 7-9 de abril de 2005.

Delgado Wise, Raúl y James Cypher (2005), “The Estrategic role of Labor in Mexico's Subordinated Integration into the US Production System Under NAFTA", documento de trabajo 12/11/2005, Zacatecas, Doctorado en Estudios del Desarrollo, Universidad Autónoma de Zacatecas. 
Delgado Wise, Raúl y Miguel Moctezuma (1993), "Metamorfosis migratoria y evolución de la estructura productiva de Zacatecas", Regiones, 1 (1), Guanajuato, pp. 107-120.

Delgado Wise, Raúl, Humberto Márquez y Héctor Rodríguez (2004), "Organizaciones transnacionales de migrantes y desarrollo regional en Zacatecas", Migraciones Internacionales, 4, Colegio de la Frontera Norte, Tijuana, pp. 159-181.

Delgado, Raúl y Héctor Rodríguez (2005), “Los dilemas de la migración y el desarrollo en Zacatecas: el caso de la región de alta migración internacional", en Raúl Delgado y Beatrice Knerr (coords.), Contribuciones al análisis de la migración internacional y el desarrollo regional en México, Miguel Ángel Porrúa-Universidad Autónoma de Zacatecas, México.

División de Población de Naciones Unidas (2006), "World Population Prospects: The 2004 Revision and World Urbanization Prospects: The 2003 Revision", http://esa.un.org/unpp, 23 de marzo de 2006.

Faist, Thomas (2005), "Espacio social transnacional y desarrollo: una exploración de la relación entre comunidad, Estado y mercado", Migración y Desarrollo, 5, Red Internacional de Migración y Desarrollo, Zacatecas, pp. 2-34.

Fomin (Fondo Multilateral de Inversiones) (2004), "Remesas hacia América Latina y el Caribe. Metas y recomendaciones", BID, Fomin, Lima, http://idbdocs.iadb.org/wsdocs/getdocument. aspx?docnum $=565875,22$ de noviembre de 2005 .

Fox, Jonathan (2005), "Repensar lo rural ante la globalización: la sociedad civil migrante", Migración y Desarrollo, 5, Red Internacional de Migración y Desarrollo, Zacatecas, pp. 35-58.

García Zamora, Rodolfo (2003), Migración, remesas y desarrollo local, Universidad Autónoma de Zacatecas, México.

García Zamora, Rodolfo (2005), Migración, remesas y desarrollo. Los retos de las organizaciones migrantes mexicanas en Estados Unidos, Universidad Autónoma de Zacatecas, México. 
Glick-Schiller, Nina, Linda Basch y Cristina Blanc-Stanton (1992), "Transnationalism: A New Analytic Framework for Understanding Migration", Annals of the New York Academy of Science, 645, Nueva York, pp. 1-24.

Goldring, Luin (1999), "Desarrollo, migradólares y la participación ciudadana de los norteños en Zacatecas", en Miguel Moctezuma y Héctor Rodríguez (comps.), Impacto de la migración y las remesas en el crecimiento económico regional, Senado de la República, México.

Guarnizo, Luis (1998), “The Rise of Transnational Social Formations: Mexican and Dominican State Responses to Transnational Migration", Political Power and Social Theory, 12, San Diego, pp. 45-94.

Guarnizo, Luis (2006), Los y las colombianas londinenses, Informe para la oIM, Universidad de California, California.

Iglesias, Enrique (2002), "Las remesas como instrumento de desarrollo: una conferencia regional”, www.revistainterforum.com/ pdf/121001DiscursoIglesia.pdf, 7 de enero de 2005.

INEGI (Instituto Nacional de Estadística, Geografía e Informática) (1990), XI Censo de Población y Vivienda 1990, Inegi, México.

INEGI (Instituto Nacional de Estadística, Geografía e Informática) (1995), I Conteo de Población y Vivienda 1995, INEGI, México.

INEGI (Instituto Nacional de Estadística, Geografía e Informática) (2000), XII Censo General de Población y Vivienda 1990, INEgI, Aguascalientes.

INEGI (Instituto Nacional de Estadística, Geografía e Informática) (2000a), Censo general de población y vivienda, INEGI, México.

INEGI (Instituto Nacional de Estadística, Geografía e Informática) (2000b), Niveles de bienestar en México, México, INEGI.

INEGI (Instituto Nacional de Estadística, Geografía e Informática) (2005), II Conteo de Población y Vivienda 2005, INEGI, Aguascalientes. 
INEGI (Instituto Nacional de Estadística, Geografía e Informática) (2005), Encuesta Nacional de Ocupación y Empleo 2005, INEGI-STPS, Aguascalientes.

INEGI-STPS (Instituto Nacional de Estadística, Geografía e InformáticaSecretaría de Trabajo y Previsión Social) (2000), Encuesta Nacional de Empleo 2000, INEGI-STPs, Aguascalientes.

Márquez, Humberto (2005), "La construcción social de un proyecto de desarrollo alternativo en una zona de alta migración internacional. Una aproximación a partir de las potencialidades del migrante colectivo zacatecano", en Raúl Delgado Wise y Beatrice Knerr (coords.), Contribuciones al análisis de la migración internacionaly el desarrollo regional en México, Miguel Ángel Porrúa-Universidad Autónoma de Zacatecas, México.

Márquez, Humberto (2006a), "El desarrollo participativo transnacional basado en las organizaciones de migrantes", Problemas del Desarrollo, 37 (144), Universidad Nacional Autónoma de México, México, pp. 121-144.

Márquez, Humberto (2006b), "Controversias en el análisis económico local basado en las remesas de los migrantes", Análisis Económico, xxi (47), Universidad Autónoma Metropolitana, México, pp. 307-330.

Márquez, Humberto (2007), "Desmantelamiento de la soberanía laboral y dependencia de las remesas en México", ponencia presentada en el Primer Congreso Internacional Migraciones Globales: Población en Movimiento, Familia y Comunidades Migrantes, Mazatlán, México, 21-24 de marzo.

Márquez, Humberto, Raúl Delgado Wise y Óscar Pérez Veyna (2006), "Precarización de la fuerza de trabajo mexicana bajo el proceso de reestructuración productiva estadounidense", Theomai, 14, Universidad Nacional de Quilmes, Buenos Aires, pp. 92-109.

Meza, Claudia y Humberto Márquez (2005), “Cambios en el patrón migratorio y pobreza en Zacatecas", en Raúl Delgado y Beatrice Knerr (coords.), Contribuciones al análisis de la migración internacional y el desarrollo regional en México, Miguel Ângel PorrúaUniversidad Autónoma de Zacatecas, México. 
Mines, Richard (1981), "Developing a Community Tradition of Migration to the United States. A Field Study in Rural Zacatecas, Mexico, and California Settlement Areas", Monographs in U.S.-Mexican Studies, 3, La Jolla, Cal., Program in United States-Mexican Studies, University of California, 219 pp.

Moctezuma, Miguel (1999), "Redes sociales, comunidades filiales, familias y clubes de migrantes. El circuito migrante Sain Alto, Zac.-Oakland, Ca.", tesis de doctorado, El Colegio de la Frontera Norte, Tijuana.

Moctezuma, Miguel (2005a), "Hacia una tipología de los migrantes internacionales con base en su capacidad de inversión”, en Raúl Delgado Wise y Beatrice Knerr (coords.), Contribuciones al análisis de la migración internacional y el desarrollo regional en México, $\mathrm{Mi}$ guel Ángel Porrúa-Universidad Autónoma de Zacatecas, México.

Moctezuma, Miguel (2005b), "Morfología y desarrollo de las asociaciones de migrantes mexicanos en Estados Unidos. Un sujeto social y político extraterritorial", Migración y desarrollo, 5, Zacatecas, pp. 59-85.

Moctezuma, Miguel y Óscar Pérez (2006), La juventud de Zacatecas en un contexto de alta migración y bajas oportunidades, informe de investigación del proyecto La juventud en Zacatecas en 2005, Instituto Nacional de la Juventud-Universidad Autónoma de Zacatecas, México.

ONU (Organización de las Naciones Unidas) (2006), "Seguimiento de la población mundial, con especial referencia a la migración internacional y el desarrollo", Informe del secretario general, E/ CN.9/2006/3, 25 de enero, Nueva York.

Peña, Ana Alicia (1995), La migración internacional de fuerza de trabajo (1950-1990): una descripción crítica, Universidad Nacional Autónoma de México-Cambio XXI, México.

Petras, James, Henry Veltmeyer, Luciano Vasapollo y Mauro Casadio (2004), Imperio con imperialismo. La dinámica globalizadora del capitalismo neoliberal, Editorial de Ciencias Sociales, La Habana. 
Portes, Alejandro (2005), "Convergencias teóricas y evidencias empíricas en el estudio del transnacionalismo de los inmigrantes", Migración y Desarrollo, 4, Red Internacional de Migración y Desarrollo, Zacatecas, pp. 2-19.

Rouse, Roger (1991), "Mexican migration and the Social Space of Postmodernism", Diaspora, 1, La Jolla, pp. 8-23.

Recibido: 1 de junio de 2007. Aceptado: 18 de junio de 2009.

Humberto Márquez-Covarrubias. Es doctor en estudios del desarrollo, es profesor-investigador del Doctorado en Estudios del Desarrollo en la Universidad Autónoma de Zacatecas. Su línea de investigación actual se centra en desarrollo y migración en América del Norte. Entre sus publicaciones más recientes se encuentran: en coautoría, "Para entender la migración a Estados Unidos. El papel de la fuerza de trabajo barata mexicana en el mercado laboral transnacional", Problemas del Desarrollo, Universidad Nacional Autónoma de México, 38 (149) (2007); “Migración y desarrollo en México: entre la exportación de fuerza de trabajo y la dependencia de las remesas", Región y sociedad, El Colegio de Sonora, XIX (39) (2007); en coautoría, Espejismos del río de oro. Dialéctica del desarrollo y la migración en México en el contexto de la integración neoliberal a Estados Unidos, Miguel Ángel Porrúa-Universidad Autónoma de Zacatecas, México (en prensa). 